University of Rhode Island

DigitalCommons@URI

Open Access Dissertations

1976

\title{
The Effect of Two Competitive Conditions and a Non-Competitive Condition on Performance and Retention on a Recognition Task
}

Thomas J. Comiskey

University of Rhode Island

Follow this and additional works at: https://digitalcommons.uri.edu/oa_diss

\section{Recommended Citation}

Comiskey, Thomas J., "The Effect of Two Competitive Conditions and a Non-Competitive Condition on Performance and Retention on a Recognition Task" (1976). Open Access Dissertations. Paper 915. https://digitalcommons.uri.edu/oa_diss/915

This Dissertation is brought to you for free and open access by DigitalCommons@URI. It has been accepted for inclusion in Open Access Dissertations by an authorized administrator of DigitalCommons@URI. For more information, please contact digitalcommons-group@uri.edu. 
THE EFFECT OF TWO COMPETITIVE CONDITIONS AND A NON-COMPETITIVE CONDITION ON PERFORMANCE AND RETENTION ON A RECOGNITION TASK

\section{BY}

\section{THOMAS J. COMISKEY}

A Dissertation Submitted in Partial Fulfillment of the Requirements for the Degree of

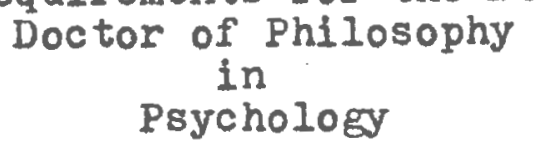

UNIVERSITY OF RHODE ISLAND

1976 
Based on a review of the literature on competition, several hypotheses on the effects of competitive instructional set on both speed and accuracy measures were explored using a paired associate learning paradigm. One hundred and forty second graders ( 70 boys and 70 girls) were randomly assigned to three instructional treatments: speed competition, accuracy competition and non-competition. The competitive groups were further divided into relative positions of win, lose and tie; subjects were equally divided by sex. Although the subjects in the speed cornpetition group performed significantly faster than subjects in the other conditions, no significant differences were found between any of the treatment conditions and the non-competitive condition on number of errors in performance. Indications were that males and females may employ a different strategy approach to noncompetitive situations but that both respond equally to a competitive situation. Several possible explanations for these results are discussed. The implications of these results for education indicate that care and caution should be used in applying competitive instructional sets as a universal classroom technique. 


\section{Acknowledgments}

The work of many people went into making this research possible. The cooperation of the local school systems, principals, teachers, parents and children, was especially appreciated and, without them, there would have been no project. The University of Rhode Island was also generous in their loan of equipment and calculators.

Gratitude must be offered to Dr. Al Silverstein for his comments and suggestions on the design employed, to Dr. Nelson Smith whose ability with instrumentation and generous offering of his time and attention were crucial factors; to Dr. Wayne Velicer who provided not only methodological assistance but needed moral support.

Special appreciation and gratitude go to Muriel B. Cohen who put in hours of time and effort collecting data, sharing ideas and giving support. She was a necessary part of this work. Appreciation is especially offered to the members of my committee - Drs, Stephen O'Keefe, Janet Kulberg, Stewart Cohen, Henry Biller and William Vosburgh - for their guidance and support. Dr. Kulberg provided the spark and inspiration for this research and remained supportive through many trying times. For this, I am grateful. The moral and literary support of Dr. Cohen was invaluable. Particular thanks and gratitude are due Dr. O'keefe for the support, assistance and advice which he has rendered throughout my graduate program at the University. 
Wy appreciation is expressed to Jean Parrish whose typing skills are only surpassed by her patience and dedication. Finally, my love, respect and admiration goes to a group of people without whom this work might never have been undertaken. The personal support and encouragement offered by Alice, Stewart, Muriel, Bob and Vicki was of incalculable importance to me both professionally and personally. Alice and Muriel receive my special thanks and appreciation: Alice - who endured months of preoccupation, depression, confusion; hiuriel whose contributions of time, effort, ideas and support are reflected in every page of this work. It is to them that this work is dedicated. 
Page

Abstract ................. . i i

Acknowledgments . . . . . . . . . . . . i ii

Table of Contents . . . . . . . . . . . v

List of Figures . . . . . . . . . . . . . vi

List of Tables . . . . . . . . . . . . . vii

Introduction . . . . . . . . . . . . 1

Purpose . . . . . . . . . . . 1

Definition ............ . 2

Task Variables .. . . . . . . . . 3

Subject Variables . . . . . . . . . 6

Situational Variables .. . . . . . . 6

Hypotheses and Prediction... . . . . . ?

likethod................ 10

Subjects ............ . . 10

Task .............. 12

Apparatus . . . . . . . . . . 13

Procedure ............. 15

Results .............. . 19

Discussion . . . . . . . . . . . 30

References . . . . . . . . . . . 39

Appendix A (Review of Definition and Paradigms) . 43

Appendix B (Tables) . . . . . . . . . 54

Appendix C (Raw Data) . . . . . . . . 61

Bibliography .. . . . . . . . . . 66 
2 Wean total errors in performance for accuracy competition groups, and a non-competitive group

Wean use of the "no response" category for three speed competition groups, three accuracy competition groups, and a non-competitive group

4

Mean latencies to respond for three speed competition groups, three accuracy competition groups, and a non-competitive group speed competition groups, three accuracy competition groups, and a. non-competitive group 
of Total Errors, "No Response" Category, Latency, Errors on Imrediate Test of Retention

2 Summary Table for $2 \times 3 \times 2$ Factorial Analysis of the "No Response" lileasure

3 Summary Table for Dunnett's t Statistic Comparing the Experimental Conditions to the Non-Competitive Conditions on the "No Response" Mleasure

4 Summary Table for $2 \times 3 \times 2$ Analysis

of Variance of Latency Measure for Speed Competition and Accuracy Competition Groups

5 Summary Table of Analysis of Covariance on the Latency Scores with the "No Response" Category as a Covariate

6 Summary Table for Dunnett's t Statistic Comparing the Experimental Conditions to the Non-Competitive Condition on Iatencies

7 Summary Table for Dunnett's $t$ Statistic Comparing the Hale Non-Competitive Group with the hale Experimental Groups and the Female Non-Competitive Group with the Female Experimental Groups on the "No Response" hieasure

A Means and Standard Deviations of Total Number of Errors Scores for Three Speed Competition Groups, Three Accuracy Competition Groups, and a Non-Competitive Group

B lifeans and Standard Deviations of "No Response" Measure for Three Speed Competition Groups, Three Accuracy Competition Groups, and a Non-Competitive Group 
C IVeans and Standard Deviations of

Latencies to Respond for Three speed

Competition Groups, Three Accuracy

Competition Groups, and a Non-Competitive

Group

D lieans and Standard Deviations of Number

of Errors on Immediate Test for Three

Speed Competition Groups, Three Accuracy

Competition Groups, and a Non-Competitive

Group

E Ifeans and Standard Deviations of Number

of Errors on Delayed Test for Three Speed

Competition Groups, Three Accuracy

Competition Groups, and a Non-Competitive Group

F Summary Table for $2 \times 3 \times 2$ Factorial Analysis of Total Errors in Performance for Speed Competition and Accuracy Competition Groups

Summary Table for Dunnett's t Statistic Comparing the Experimental Conditions to the Non-Competitive Condition

$\mathrm{H} \quad$ Summary Table for $2 \times 3 \times 2$ Analysis of Variance on Errors on Immediate Test for Speed Competition and Accuracy Competition Groups

I Summary Table for Dunnett's t statistic Comparing the Experimental Conditions to the Non-Competitive on Errors on Immediate Test of Retention

$J$

Summary Table for $2 \times 3 \times 2$ Analysis of Variance on Errors on the Delayed Test for Speed Competition and Accuracy Competition Groups

K Summary Table for Dunnett's t Statistic Comparing the Experimental Conditions to the Non-Competitive on Errors on the Delayed Test of Retention 
The concept of competition has long been of concern to educators, parents and society. For example, it may be questioned whether competition acts as a positive or negative factor in human interaction. A corollary concern of such interest is the role competition may play in enhanciner human learning. In social situations it is generally conceded that competition negates group cooperation and cohesion (Johnson \& Johnson, 1975). In contrast, competition has been considered a critical component in the acquisition and performance in various facets of learning (Hurlock, 1927; Maller, 1929; Greenberg, 1932). Although there is much debate as to the types of tasks and situations with which competition is really effective (Johnson \& Johnson, 1975), the effects of competition on learning have not been fully explored.

\section{Purpose}

The present study examined various instructional sets utilized to explore the effects of competition on accuracy; latency and retention in a paired associate task. The differential effects of emphasizing speed as opposed to accuracy in a competitive situation is considered. The effectiveness of competition in these situations is then compared to a non-competitive situation.

The review of literature shows a diversity in the definition of competition. These differences in theoretical approach result in contrasting facts involving task, subject, 
and situation. Previous results must be then interpreted with due consideration to the experimenter's choice of task, subject, and situation.

\section{Definition}

A review of the literature indicates that competition has been studied under various methodological paradigms. The very diversity of this research creates considerable difficulty in the development of a uniform theoretical approach to assessing the effects of competition and leaves many questions to be answered.

Variations in research strategy has led to several definitions of competition. Some paradigms (Deutsch, 1949; Kelley \& Thibaut, 1969) emphasize the role of motive as a precondition to examining the effects of competition. Game theory defines some forms of competition in terms of a "win-lose" situation in which the goal sought allows for delimited outcomes favoring one participant over another (Wrightsman, 1972). The "win-lose" approach has been employed by Weingarten and likechner (1966) and Lindsley (1966) to identify the parameters of competitive behavior in laboratory studies. A similar approach has been used by Clifford (1971) in school-related studies.

A modification of the "win-Iose" approach has been developed by McClintock (1972). He defines competition in a "win-lose" situation as viewing one's personal gains relative to the performance of another individual. In support, Mithaug 
(1973) suggested that this criterion, i.e. performance in relation to that of another, is a central criterion in evaluating the effects of performance in a "win-lose" situation. In the current study, competition is defined as behavior exhibited in a "win-lose" situation in which the relative gain of performance is stressed in relation to the performance of another individual.

\section{Task Variables}

The use of various tasks and methodological approaches has characterized the research on competition. In particular, research studies have emphasized the role of personal motive upon performance in competitive game situations and in motor tasks under conditions of delimited social interactions. Complementing this research, the effects of competition have been studied under school settings.

Many studies of competition have appeared under the rubric of game theory. Yet the focus of this research has been on cooperation, not competition. Moreover, tasks employed under this paradigm have stressed motive for performing rather than outcome effects. Finally, since the players' choices are interdependent, competition itself was necessarily maladaptive (HcClintock, Gallo \& Harrison, 1965). The theoretical impetus for viewing competition in a competitive game situation comes from small group theory in which cooperative behavior is seen to enhance group functioning while competition is viewed as inhibiting group performance 
(Gallo \& MCClintock, 1972; Kelley \& Thibaut, 1969).

Laboratory research has also stressed performance tasks which emphasize cooperative behavior as an adaptive response (Sidowski, Wyckoff \& Taborg, 1956; Sidowski, 1957; Kelley, Thibaut, Radloff \& Mundy, 1962; Azrin \& Lindsley, 1956). In contrast, Mithaug (1973) suggests the need to explore the full range of effects attributable to competition, particularly in situations in which a competitive posture represents a viable alternative. These effects, however, have not been fully explored in laboratory conditions.

Clifford's research $(1971,1972)$ has explored the effects of competition in academic settings. This research is particularly important since it departs from previous efforts which have been restricted to controlled laboratory situations and/or situations allowing for limited social interactions. Clifford's work offers a research model more congruent with actual classroom competition.

Several investigations have studied the effects of competition on academically-related performance tasks. liany of these studies have focused on motor tasks with a speed component. In brief, it has been demonstrated that competition increases performance on speed tasks using either motor or simple arithmetic problems (Greenberg, 1932; Hurlock, 1927; Maller, 1929).

However, Clifford questions whether these tasks are too simple to provide an adequate school analog as well as 
whether the same effects would be found in tasks which emphasized power rather than speed, In one experiment, Clifford (1971) employed a digit substitution task and had fifth and sixth graders compete on how fast they could copy figures. Her results showed that subjects in the competitive set copied more digits than subjects in the non-competitive group. In subsequent research, Clifford, Cleary and Walster (1971) employed a mathematics test emphasizing accuracy and found that a competitive set had no effect on performance. Clifford (1971) employed a word list in comparing the performance of competitive groups and a non-competitive group on a task emphasizing accuracy and not speed. Her research demonstrates that performance on a classroom-administered power test was not enhanced under competitive treatments (clifford, 1972). The task she used, however, was at the high end of the task difficulty continuum. Her results, therefore, may be attributable to the level of task difficulty rather than to the fact that the task instructions emphasized power rather than speed. In addition, no direct comparison was made between the power task and an equivalent speed task. In contrast, the current study compares performance on a task emphasizing speed with a power task, while holding the level of difficulty constant. A power task is defined as a problem-solving task in which performance is limited by time constraints.

Another task component to be considered is retention and how it is affected by a competitive set. Blair, Jones and Simpson (1968) state that motivational conditions can 
either interfere with or facilitate retention. Using a power test, Clifford (1972) found that retention was not improved under a competitive condition. However, it may be asked whether there would be a differential effect on retention based on a speed versus a power condition, employing the same task.

\section{Subject Variables}

The role of competition among males and females is of considerable interest. However, research findings on sex effects are inconclusive. Several studies (Madsen, 1967; Miller \& Thomas, 1970; Kagan \& Madsen, 1971) have found few differences between males and females in response to cooperative/competitive situations. Some studies (McKee \& Leader, 1955; Shapira \& Madsen, 1969; Nelson, 1970) report boys to be more competitive than girls. However, Kulberg and Woulff (1973) found males more competitive under some reinforcement conditions and females more competitive under other reinforcement conditions. The sex variable, therefore, will be examined in the present investigation.

Nelson (1970) and Madsen (1971), using the Madsen Cooperation Board, found that American children became more competitive with increasing age and exposure to formal education. The paired associate picture task employed in this study has been previously used by Kulberg and Woulff (1973) and Comiskey (1975) with young children in first and second grades. Second graders were used as subjects for this study since the task has been shown to be appropriate to their abilities, and they have been exposed to at least two years 
of formal education.

\section{Situational Variables}

The effect of the competitor's presence is a factor which has been of interest to researchers. Cottrell (1970) and Ryan and Strawbridge (1969) found that the competitor's presence can enhance the performance of a subject in the competitive situation. Question has arisen, however, as to whether the subject's knowledge of the competitor is an important component of this effect. Remote goals or competitors may not prove to have high motivational value, and, if they are not perceived as relevant, may have little or no effect on his/her behavior (Cartwright \& $Z_{a}$ nder, 1953). A prior question may be asked as to the effects of competition under conditions in which this variable is held to a minimum (Davis, Laughlin \& Komorita, 1976). This study uses a "reported other" rather than an actual competitor in surveying the effects of competition on performance and retention of a learning task.

A second variable of concern to researchers is status among competitors. Smith (1959) concluded that there is a tendency for subjects who viewed their performance as successful to raise their level of aspiration and for subjects who viewed their performance as unsuccessful to lower their level of aspiration. Strong (1963), controlling for subject's ability level, found that in competitive situations subjects preferred to compete with persons of similar ability and that such 
pairing enhances competition. It will be questioned whether children view competition differently depending on whether they are winning, losing, or tied.

\section{Hypotheses and Prediction}

This study investigates the effects of different types of competitive situations on performance and retention on a recognition learning task. Specifically, it asks whether an instructional set emphasizing accuracy versus speed will lead to more effective performance among competitive groups in contrast with a non-competitive group. Further, it is asked whether conditionsassociated with performance of a competitor (i.e. win, lose or tie) will effect performance. The central hypotheses of this study are:

(1) Competitive instructional set is more effective in assisting the learning of recognition tasks than is a non-competitive instructional set.

(2) Competitive instructional set is more effective in assisting the learning of recognition tasks which emphasize speed rather than accuracy.

(3) Competitive instructional set enhances retention more than does non-competition.

(4) Competitive instructional set enhances retention when speed is emphasized more than accuracy.

(5) Competitive instructional set is more effective when the individual is near his competitor in performance rather than when he is ahead or behind. 
(6) Competitive instructional set is equally effective among males and females in facilitating performance. The following predictions are tested:

(1) a. The competitive groups will make fewer errors than the non-competitive group.

b. The competitive groups will perform faster than the non-competitive group.

(2) a. The speed competition group will make fewer errors than the accuracy competition group.

b. The speed competition group will perform faster than the accuracy competition group.

(3) The competitive groups will make fewer errors on the retention tasks than does the non-competitive group.

(4) The speed competition group will make fewer errors than the accuracy competition group on the retention tasks.

(5) Subjects in the tied condition will make fewer errors than those in the other two positions.

(6) There will be no difference in the performance of males and females in reference to either errors or latency. 
Wethod

Subjects

One hundred and forty second graders ( 70 boys and 70 girls from five local elementary schools in South Kingstown, Rhode Island) were selected for this study. Parental permission was a necessary condition for inclusion. Males and females were separately and randomly assigned to the different treatment conditions so as to assure an equal number of males and females in each group. The list from each school was assigned separately in order to maintain the same proportion of subjects from any one school in each of the groups.

A further criterion was used to screen subjects for participation, Mallory (1972) found that among second graders there is a distinction between visualizers and verbalizers and that visualizers have superior performance on pictorial paired associate tasks. Therefore, there would be students for whom such a task would be too easy or too difficult. In order to provide a check on the appropriateness of this task, those subjects who did not answer at least one right on the practice trial or those who answered all the items correctly on the third trial were replaced as subjects. This provided a control for those subjects for whom the task was inappropriate. In addition, this procedure permitted differentiation of the ahead and behind position on a pre-programmed basis.

When a subject was eliminated on either of these criteria, an additional subject was randomly drawn from the 
remaining names on the appropriate list of males or females in the different schools. Seventeen subjects were replaced: four because they did not understand the task, thirteen because the task proved too easy for them. Those eliminated were evenly divided between males and females (one more female was dropped than males) and were spread across all treatment conditions. No discernible pattern as far as IQ, SES or achievement was found.

Assignment to Groups

One hundred and forty subjects were assigned to treatment conditions, according to the following designs

\begin{tabular}{|c|c|c|c|c|}
\hline & & Win & Lose & Tie \\
\hline \multirow{2}{*}{$\mathrm{Sp}$} & II & $N=10$ & $N=10$ & $N=10$ \\
\hline & $F$ & $N=10$ & $N=10$ & $N=10$ \\
\hline \multirow{2}{*}{ Acc } & $M$ & $N=10$ & $N=10$ & $N=10$ \\
\hline & $\mathrm{F}$ & $N=10$ & $N=10$ & $N=10$ \\
\hline \multirow{2}{*}{ Control } & $M$ & $N=10$ & & \\
\hline & $\mathrm{F}$ & $N=10$ & & \\
\hline
\end{tabular}

Figure 1. Schematic representation of treatment conditions

Subjects were assigned to one of three conditions: speed competition, accuracy competition and non-competition. The speed competition condition emphasized answering correctly first, the accuracy competition condition emphasized the total number right, and the non-competitive group was simply asked 
to perform the task with no reference to a comparative group. The subjects in the competitive groups were further assigned to a competitive positive relative to the other person win, lose or tie. This assignment resulted in 14 cells with 10 children to a cell.

$\underline{\text { Task }}$

Clifford (1972) asked what are the effects of task difficulty on competition. However, as discussed earlier, there is some question as to the range of difficulty such a task will assume. Consequently, a task was sought which would occupy the middle-range of difficulty, being appropriate to second graders. Lynch and Rohwer (1973) found that pictures are better recognized and matched than words. A paired associate pictorial task was deemed an appropriate one for second graders (Comiskey, 1975).

The task and procedure was adapted from Kulberg (1967). In this procedure the subject.was first presented with seven pairs of pictures and was asked to associate the stimulus-response pictures with each other. After the presentation of all seven pairs, each of the stimulus pictures was presented alone and in a different order than originally presented. For each picture, the subject was required to recall each of the appropriate associated pairs. This method was adapted to a recognition format rather than a recall one in order to facilitate information-gathering with respect to latency of response. 
The list of paired associate pictures consisted of seven pairs of pictures selected from the Peabody Picture Vocabulary Test on the basis of having low verbal association (Palermo \& Jenkins, 1964). On each trial, the pairs and the stimulus pictures were randomly ordered. One trial consisted of the presentation of the seven pairs of pictures and the seven stimulus pictures.

\section{Apparatus}

The pictures were prepared on $2 \times 2$-inch black and white slides, seven with both the stimulus-response items and seven with just the stimulus items. These were placed in a Kodak Carousel projector and set to change automatically every eight seconds. The projector was set on a table behind and above the subject and projected a picture ( 1 ' $x 1^{\prime}$ ). onto a screen just in front of the subject. The order of the pairs and of the stimuli were randomly determined so as to avoid any serial learning effects. Each subject was presented with the same sequence, One trial consisted of the presentation of the seven pairs and then the seven stimulus cards. Two blanks were inserted between the trials, thus allowing for a 16-second rest period. Each trial took two minutes and there were seven trials in each series of presentations.

To facilitate recording, an individual station was constructed on which the subject would be able to respond. This station was constructed with one-quarter-inch plywood and covered with white contact paper. Seven buttons were set into the workboard directly in front of the subject. Above each of 
these buttons was one of the response pictures and a light. The mechanism was designed so that when the subject responded to the stimulus item, he/she could push the button in front of the picture he/she thought was the correct response. The light over that picture would remain on after the button was released so that the subject could still tell which picture he/she had selected. Near the top of the station there were two lights under manual control of the experimenter which indicated whether the answer chosen was correct or incorrect. Both lights extinguished as the next slide was presented.

In addition to errors, latencies were also recorded. A timer was attached to the lighting system; when a response was made by the subject, the timer was set to stop and record the latencies. An electric eye was placed in the screen and connected to the timer. Changing of the slides would restart the timer, thus allowing for continuous recording of the next latencies. Latencies were recorded cumulatively for each series of presentations:

Feedback was manually controlled by the experimenter and was provided on $5 \times 8$-inch index cards, indicating winning $(+1$ to +7$)$, losing $(-1$ to -7$)$, or tied (no numbers). In addition, a set of cards was prepared for the non-competitive group reading trials (numbers 1 to 7 ). An index card holder was placed to the immediate left of the subject within direct line with his/her vision. At the end of each trial, the appropriate card was placed in the holder by the experimenter. 
The test of retention required the subject to match the previously presented stimulus pictures with their accompanying pair.

\section{Procedure}

The equipment was placed in a $20 \times 10$-foot room of a mobile office which was then moved from school to school. Subjects were seen individually by one of the experimenters, either a male or a female, in a counterbalanced manner controlling for sex of experimenter.

In order to acquaint the subject with the task, all participants went through a training phase in which they were asked to learn a practice list of four pairs of pictures mounted on $3 \times 5$-inch index cards and slides. Each pair was presented followed by a card containing a single stimulus picture.

The following instructions were read:

This is a task to see how well you can remember pictures. First, you'll see a pair of pictures like this (illustration pair); then, you'll see only the picture on this side (illustration stimulus card). Your job is to guess what goes here. To help you guess, here are the pictures of the answers (point to pictures on station). All you have to do is to push the button in front of the picture that you think goes here. When you do, one of these lights will light up to show you which one you picked. Which one would you push for this (illustration)? $\mathrm{OK}$, and this lit up to show you which one you picked.

Now these lights here will show you whether you are right (turn on green, yes) or wrong (turn on red, no). In this case, you're right (yes). Let's try these, OK? 
The subject was then presented with the four practice pairs and the stimulus cards to which he/she was asked to respond.

The experimenter continued with the following instructions:

Now that you have the idea, I would like to continue to practice with these pictures - only you'll now see the pictures up here on the screen. First, you will see the four pairs; then you will see only the picture on this side. Push the button in front of the picture you think goes with the one up on the screen.

At this point, any subject who did not get at least one right was replaced by a student from the alternative list. After the practice trial was run, the subject was further instructed:

OK, now that you've practiced, I will show you a new set of pictures on the screen. First, you will see the pairs and then just the stimulus picture. All you do is push the button in front of the picture you think goes with it.

Then, depending on treatment condition, the following instructions were given:

Control: When you are finished with each set or trial, a card like this will be put in front of you to show you that a new set is coming up. So, a card like this would mean that this is the second trial.

Speed Condition: This has already been done at another school, and I would like to see how well you do compared to another child at that other school. The machine already has that other child's answers and how quickly. that child did them. I would like to see how quickly you can get the right answers compared to that child. To help you know how well you're doing, after each set of pictures, I will place a card like this in front of you. It will show you whether you are winning, losing or tied. So, if you see a card like this, it means that out of all the ones you've done so far, the other person has gotten four faster than you have. This would mean that you have gotten four faster. Now, what would this mean? Remember, the score tells you whether you are getting the answers faster than the other child. You will know if they are right or wrong by these lights. Any questions? OK? Ready! 
Accuracy Condition: This has already been done at another school, and I would like to see how well you do compared to another child at that other school. The machine already has that other child's answers. I would like to see how many you can get right compared to that other child. To help you know how well you are doing, after each set of pictures, I will place a card like this in front of you. It will show you whether you are winning, losing or tied. So, if you see a card like this, it would mean that out of all the ones you've done so far, the other person has four more right than you do. This would mean that you would have four more right than they do. Now, what would this mean? Remember, the score telis you how many you are getting right compared to the other child. You will know if they are right or wrong by these lights. Any questions? OK? Ready!

Since the comparison competitive child was a "reported other" and his/her performance was controlled by the experimenter, a prearranged comparison score was provided at the end of each trial to each subject. . Over the first three trials, subjects found themselves winning, losing or tied with the fictitious competitor. These same assigned positions were maintained over the next four trials.

Each subject's responses were recorded in terms of correct, incorrect, and no response. In addition, latencies associated with each trial were recorded. At the end of the task, the subject was asked to match the stimulus and response pictures correctly on the test of retention. This procedure was repeated after 24 hours.

In the debriefing phase, the experimenter thanked the child and asked him/her not to tell the other children about the task. This time also allowed the experimenter to counter any possible negative reactions to the experimental conditions and to check the effect of the manipulations. 
The present study encompasses two treatment conditions (speed and accuracy competition) under three levels of competition (win, lose and tie) for both males and females. In addition, there was a non-competitive group which received no instructions or feedback in relation to win, lose or tie. Five dependent measures were employed. All the errors a subject made in learning the task were totaled to yield one number, a total errors in performance score. A particular type of error, the "no response" was partialed out from this total score and analyzed separately in order to observe strategy used by subjects in dealing with competitive situations. Latencies were recorded, and the total time needed to respond to all the stimulus pictures was used as a single score. Latencies for no responses were recorded as full time of exposure ( 8 seconds). Total errors on the immediate and delayed tests of retention were also recorded. 
Analyses were done on five dependent measures: total errors on performance, use of the "no response" category, latency scores, and errors associated with immediate and delayed test of retention. Total errors in performance during the seven trials included the "no response" measure. The "no response" measure was then partialed out and analyzed separately. The .05 level of significance was adopted for all statistical tests. Means and standard deviations for the five dependent measures are reported in Tables A-E.

As a preliminary procedure, the $F \max$ test (winer, 1972) for homogeneity of variance was applied to the data. For all analyses, excepting the "no response" category, there was no violation of the homogeneity of variance assumption. The "no response" category was statistically significant at the .05 level (F $\max =16.74, p .05$ ). Therefore, some caution need be assumed in interpreting data associated with this measure.

In order to examine the relationship between latency and errors and latency and "no response", correlations were computed for the number of total errors on performance, no response, latency and the number of errors on the immediate test of retention. These results are reported in Table 1. In viewing these data, it may be observed that significant relationships were found between the number of errors in performance and latency, and the number of errors on the immediate test as well as among latency and the "no 
TABLE 1

Intercorrelation Between the Number of Total Errors, No Response Category, Latency, Errors on Immediate Test of Retention

\begin{tabular}{llllll}
\hline & $N$ & 1 & 2 & 3 & 4 \\
\hline 1) Total Errors & $(140)$ & 1.000 & & \\
2) No Response & $(140)$ & .2241 & 1.000 & \\
3) Latency & $(140)$ & $.4645^{*}$ & $.6671^{*}$ & 1.000 & \\
4) Errors on & $(140)$ & $.6473^{*}$ & .1116 & $.3449^{*}$ & 1.000 \\
Retention Test & & & & & \\
${ }^{*} .05$ & & & & & \\
\hline
\end{tabular}

response" category. Correspondingly, in subsequent analyses, measures of covariance was used wherever appropriate.

Analysis of Total Number of Errors During Performance lineans for the speed competition ( $s p)$, accuracy competition (acc), and non-competitive groups ( $\mathrm{nc}$ ) are depicted in Figure 2.
16.0
15.5
15.0
14.5
14.0
13.5
13.0
12.5
12.0
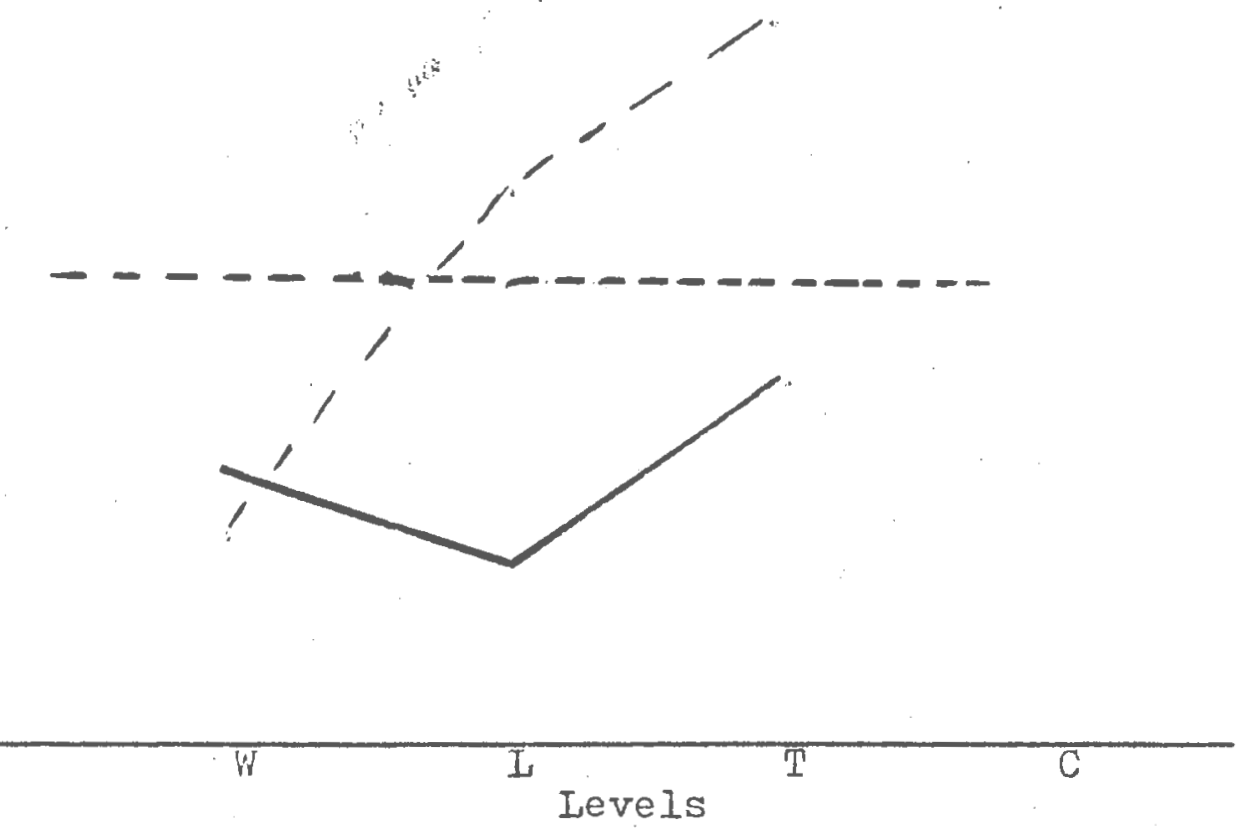

Figure 2. Mean total errors in performance for three speed competition groups ( $\mathrm{sp}$ ), three accuracy competition groups (acc) and a non-competition (nc) group 
The number of errors recorded under the speed competition and the accuracy competition group were analyzed by a 2 (competitive condition) $\times 3$ (level of position) $\times 2$ (sex) factorial analysis of variance design (Winer, 1971). Results of this analysis are presented in Table F.

No significant differences for the total number of errors were found for condition, level or sex. All interactions were also insignificant.

An analysis was performed between each of the experimental cells and the non-competitive group using Dunnett's adaptation of the $t$ statistic (Winer, 1971). Results of this analysis are shown in Table $G$.

No significant differences on the total number of errors were found between any of the experimental conditions and the control group.

Analysis of the "No Response" iNeasure

In order to observe strategies used in approaching the task, the "no response" category was partialed out from the total error score and was viewed as a particular kind of response one may choose in a competitive situation. The means for the speed competition ( $s p$ ), accuracy competition (acc), and non-competitive (nc) groups are depicted in Figure 3.

A 2 (condition) $\times 3$ (level) $\times 2$ (sex) factorial analysis of variance (Winer, 1971) for "no response" category was performed. Although the test for homogeneity of variance was statistically significant, the analysis was performed in 


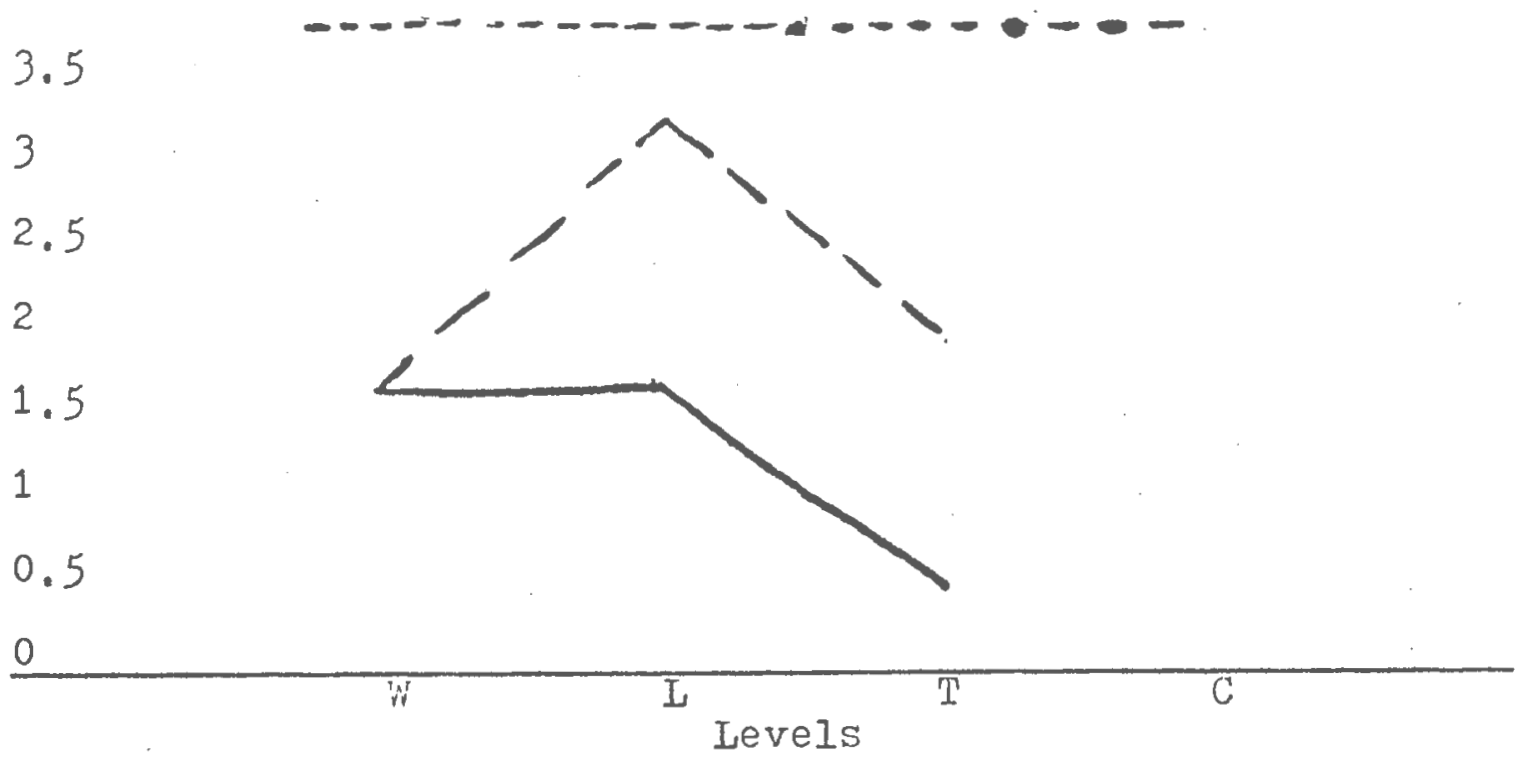

Figure 3. Mean use of the "no response" category for speed competition groups (sp), accuracy competition groups (acc), and a non-competitive (nc) group

the light of the Norton (1952) and Boneau (1960) findings pertaining to the robust nature of this measure and with the realization that the tests of significance could not be held as stringent at the .05 level originally adopted. These results are reported in Table 2 .

\section{TABLE 2}

Summary Table for $2 \times 3 \times 2$ Factorial Analysis of the "No Response" Measure

\begin{tabular}{|c|c|c|c|c|}
\hline Source & Sum of Squares & $\begin{array}{c}\text { Degrees of } \\
\text { Freedom }\end{array}$ & $\begin{array}{l}\text { Miean } \\
\text { Square } \\
\end{array}$ & $F$ \\
\hline $\begin{array}{l}\text { C (condition) } \\
\text { L (level) } \\
\text { S (sex) } \\
\text { CL } \\
\text { CS } \\
\text { LS } \\
\text { CLS } \\
\text { Error Term }\end{array}$ & $\begin{array}{r}17.6333 \\
40.2000 \\
3.3333 \\
1.2666 \\
0.8333 \\
1.2666 \\
2.4666 \\
524.1924\end{array}$ & $\begin{array}{r}1 \\
2 \\
1 \\
2 \\
1 \\
2 \\
2 \\
108\end{array}$ & $\begin{array}{r}17.6333 \\
20.1000 \\
3.3333 \\
0.6333 \\
0.8333 \\
0.6333 \\
1.2333 \\
4.8536\end{array}$ & $\begin{array}{l}3.6330^{3 k} \\
4.1412^{3 k} \\
0.6868 \\
0.1305 \\
0.1717 \\
0.1305 \\
0.2541\end{array}$ \\
\hline${ }^{*} \mathrm{p} \quad .05$ & & & & \\
\hline
\end{tabular}


Significant mean effects were obtained between treatment conditions and level of competition. The effects of condition are evident in the less frequent use of the "no response" category by the subjects in the speed competition (sp) condition than among subjects in the accuracy competition (acc) condition $(\bar{X}(s p)=1.31 ; \bar{X}(a c c)=2.08)$. A Newman-Keuls test for levels of significance shows that subjects in the tied group used the "no response" measure significantly. less often than the subjects performing under the other two levels $(\bar{X}($ tied $)=.90 \cdot \bar{X}($ win $)=1.95 ; \bar{X}($ lose $)=2.25)$ while win and lose did not differ significantly.

A Dunnett's t statistic (Winer, 1971) was performed between each of the experimental conditions and the noncompetitive group. Results are reported in Table 3.

\section{TABLE 3}

Summary Table for Dunnett's t Statistic Comparing the Experimental Conditions to the Non-Competitive Conditions on the "No Response" Measure

\begin{tabular}{lllllll}
\hline & \multicolumn{2}{c}{ Speed } & \multicolumn{3}{c}{ Accuracy } \\
& Win & Lose & Tied & Win & Lose Tied \\
\hline $\begin{array}{l}\text { Non-Competitive } \\
\mathrm{p} .05\end{array}$ & $2.44^{*}$ & $2.38^{*}$ & $3.84^{*}$ & 1.86 & 1.22 & $2.91^{*}$ \\
\hline
\end{tabular}

Significant differences were found for each of the three levels of competition on the speed competition condition and the non-competitive condition as well as between the tied group of the accuracy competition condition and the non- 
competitive condition. Each of these groups made significantly less use of the "no response" measure than the non-competitive group.

Analysis of Latency to Respond

Weans for the speed competition ( $s p$ ), accuracy

competition ( $\mathrm{acc}$ ), and non-competitive ( $\mathrm{nc}$ ) groups are depicted in Figure 4.

1550

1500

1450

1400

1350

1300

1250

1200

1150

1100

1050

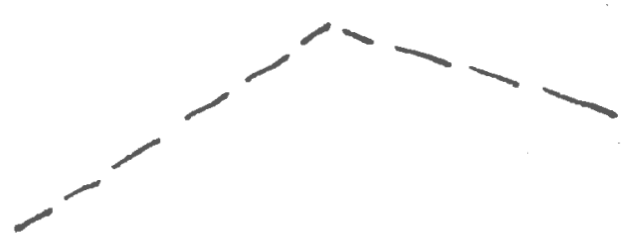

1000

W Levels ${ }^{\text {T }}$ C

Figure 4. Mean latencies to respond for three speed competition groups ( $\mathrm{sp}$ ), three accuracy competition groups (acc), and a non-competitive group (nc)

A 2 (condition) $\times 3$ (level) $\times 2$ (sex) factorial analysis (Winer, 1971) was applied to the data on latencies, and the results are reported in Table 4. 
TABLE 4

Summary Table for $2 \times 3 \times 2$ Analysis of Variance of Latency Measure for Speed Competition and Accuracy Competition Groups

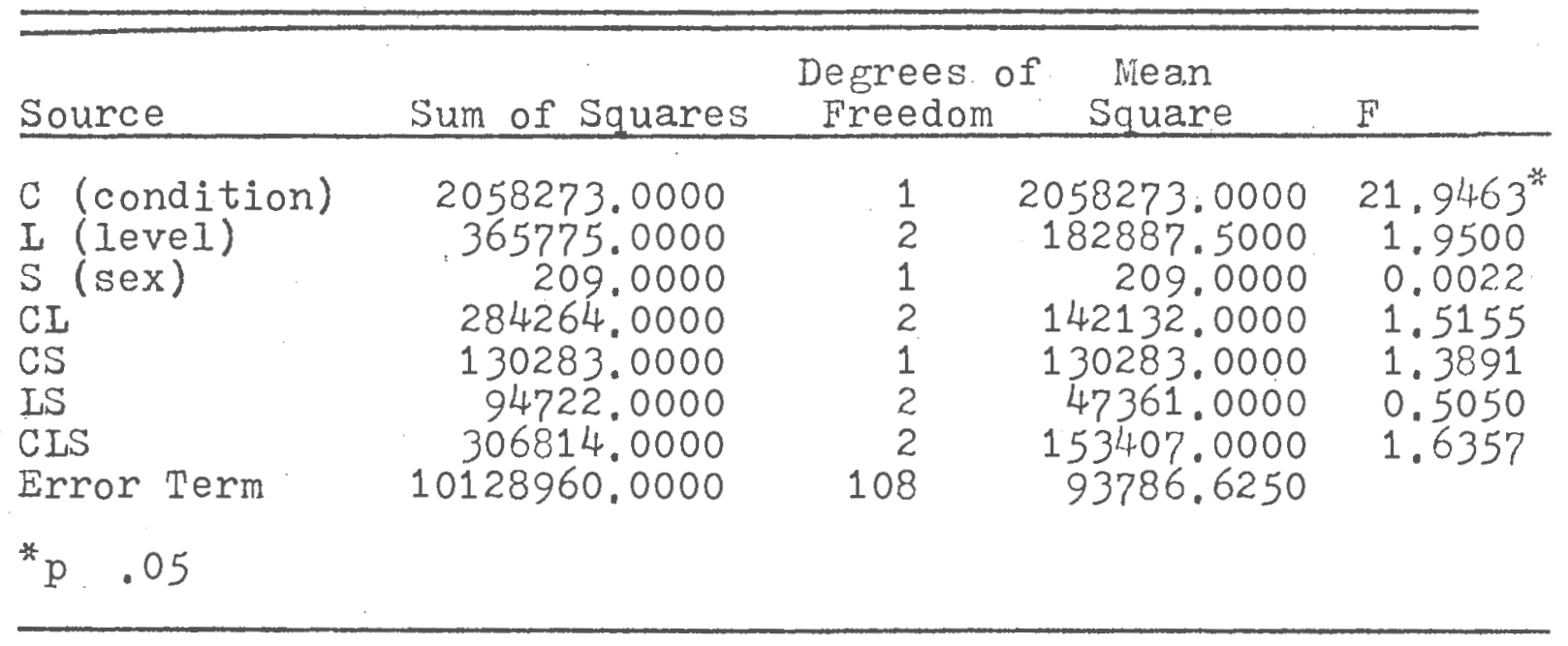

There is a significant main effect found between the two groups on condition with the speed competition ( $\mathrm{sp}$ ) groups taking significantly less time to respond than the accuracy (acc) groups $(\bar{X}(s p)=120.9 ; \bar{X}(a c c)=147.1)$.

Since there was a correlation between the "no response" category and latencies, an analysis of covariance (Winer, 1971) was performed, using "no response" as the covariate. These results are reported in Table 5. When "no response" is used as a covariate, the difference between the groups in terms of the speed at which they perform the task remains statistically significant. Therefore, the time difference in performance cannot be simply attributed to the use of the "no response" category.

A comparison was then made between each of the experimental groups and the non-competitive group, using Dunnett's $t$ statistic (winer, 1971). Results are reported in Table 6. 
TABLE 5

Summary Table of Analysis of Covariance on the Latency Scores with the

"No Response" Category as a Covariate

\begin{tabular}{|c|c|c|c|c|}
\hline Source & Sum of Squares & $\begin{array}{l}\text { Degrees of } \\
\text { Freedom }\end{array}$ & $\begin{array}{l}\text { lilean } \\
\text { Square }\end{array}$ & $\mathrm{F}$ \\
\hline $\begin{array}{l}\text { C (condition) } \\
\text { L (level) } \\
\text { S (sex) } \\
\text { CL } \\
\text { CS } \\
\text { LS } \\
\text { CLS } \\
\text { Covariates } \\
\text { Covariate } 2 \\
\text { K (CLS) }\end{array}$ & $\begin{array}{r}1143357.0000 \\
48385.0000 \\
18565.0000 \\
222263.0000 \\
81318.0000 \\
145080.0000 \\
184838.0000 \\
3590860.0000 \\
3590859.0000 \\
6538100.0000\end{array}$ & $\begin{array}{r}1 \\
2 \\
1 \\
2 \\
1 \\
2 \\
2 \\
1 \\
1 \\
107\end{array}$ & $\begin{array}{r}1143357.0000 \\
24192.5000 \\
18565.0000 \\
111131.5000 \\
81318.0000 \\
72540.0000 \\
92419.0000 \\
3590860.0000 \\
3590859.0000 \\
61103.7383\end{array}$ & $\begin{array}{r}18.7117^{*} \\
0.3959 \\
0.3038 \\
1.8187 \\
1.3308 \\
1.1872 \\
1.5125 \\
58.7666 \\
58.7666\end{array}$ \\
\hline * $\mathrm{p} .05$ & & & & \\
\hline
\end{tabular}

\section{TABLE 6}

Summary Table for Dunnett's t Statistic Comparing the Experimental Conditions to the Non-Competitive Condition on Latencies

\begin{tabular}{lllllll}
\hline & \multicolumn{3}{c}{ Speed } & & \multicolumn{3}{c}{ Accuracy } \\
& irin & Lose & Tied & Win & Lose & Tied \\
Non-Competitive & $3.08^{*}$ & $3.09^{*}$ & $4.82^{*}$ & 1.74 & .38 & 1.25 \\
* .05 & & & & &
\end{tabular}

Significant differences were found between each of the speed competition groups and the non-competitive group with the responses to the speed condition being significantly faster than under the non-competitive condition. 

$\frac{\text { Analysis }}{\text { Retention }}$ the Number of Errors on the Immediate Test of

Means for the speed condition ( $s p)$, accuracy condition (acc) and the non-competitive (nc) groups are depicted in Figure 5.

\section{1}

1.8

1.5

1.2

.9

.6

.3

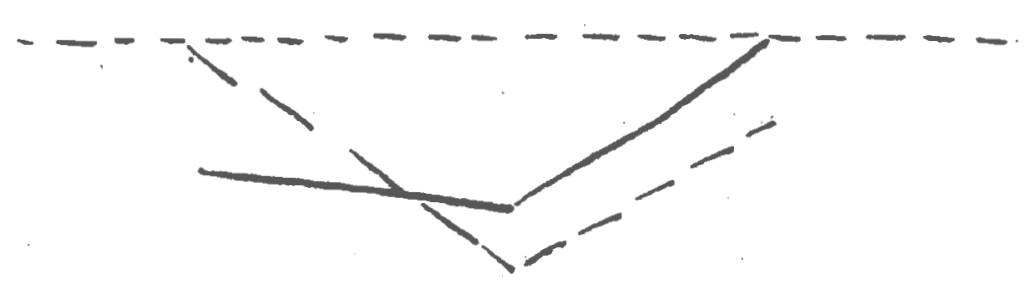

0

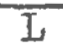

Figure 5. hean errors on immediate test for three speed competition groups ( $\mathrm{sp}$ ), three accuracy competition groups ( $a c c$ ), and a non-competitive (nc) group

A 2 (condition) $\times 3$ (level) $\times 2$ (sex) factorial analysis of variance (winer, 1971) was conducted on the error scores for the immediate test of retention. These results are presented in Table $\mathrm{H}$.

No significant differences were found for condition, level or sex. All interactions were also insignificant.

A comparison was made between the experimental groups and the non-competitive group using Dunnett's $t$ statistic. (Winer, 1971). These results are presented in Table I. 
No significant differences were obtained between any of the experimental groups and the non-competitive group on the number of errors made in the immediate test of retention. Analysis of the Number of Errors on the Delayed Retention Test Means for the delayed test of retention are reported in Tables 8-12.

A 2 (conditions) $\times 3$ (levels) $\times 2$ (sex) factorial analysis of variance (Winer, 1971) was conducted, and the results reported in Table $\mathrm{J}$.

No significant differences were found for condition, level or sex. All interactions were also insignificant.

A comparison was made between the experimental groups and the non-competitive group using Dunnett's t statistic (Winer, 1971). The results are presented in Table K.

No significant differences were obtained between any of the experimental groups and the non-competitive group on the number of errors made in the delayed test of retention. Because of the limitations of the Dunnett's $t$ statistic in comparing treatment conditions with each other (winer, 1971), it was not possible to directly test for sex difference between experimental and non-competitive groups. However, when separate analyses (Dunnett's t statistic, Winer, 1971) were conducted comparing male experimental subjects with the male control and female experimental subjects with female control, inspection of the data gave the appearance that the type of strategy used by males and females in competitive 
situations, particularly involving the use of "no response". The results are reported in Table 7.

\section{TABLE $?$}

Summary Table for Dunnett's t Statistic Comparing the Male Non-Competitive Group with the Wale Experimental Groups and the Female Non-Competitive Group with the Female Experimental Groups on the "No Response" lifeasure

\begin{tabular}{llllllll}
\hline & \multicolumn{3}{c}{ Speed } & \multicolumn{4}{c}{ Accuracy } \\
& Win & Lose & mied & Win Lose & Tied \\
\hline Male Non-Comp. & 1.47 & 1.47 & $2.64^{*}$ & 1.02 & -.29 & 2.20 \\
Female Non-Comp. & $3.20^{*}$ & $3.10^{*}$ & $4.80^{*}$ & $2.50^{*}$ & $2.30^{*}$ & $3.50^{*}$ \\
* .05 & & & & & & \\
\hline
\end{tabular}

The use of the "no response" category in the non-competitive situation was more frequent for females than for males $(\bar{X}(f)=5.1 ; \bar{X}(m)=2.5)$. These results are further supported by the significant difference in the standard deviation for the experimental female group $(F=16.81, p .01)$.

In summary, the speed competition group is faster than the accuracy competition and the non-competitive groups, but there were no significant differences between any of the groups in the number of errors associated with performance nor on the immediate test. There was a significant difference between the non-competitive group and the competitive groups on the use of "no response" as a strategy, and the speed competition group performed the task significantly faster than the other groups without any significant difference in errors. 
The present study investigated the influence of varied competitive conditions on performance and retention in a recognition learning task. It was hypothesized that subjects in the competitive conditions would make fewer errors in performance and retention than subjects in the non-competitive condition. This prediction was not confirmed. It was also predicted that the competitive conditions would produce shorter latencies in performance than the noncompetitive group. This prediction was confirmed for one treatment condition (the speed competition). There was no statistically significant difference between the accuracy competition group and the non-competitive group in terms of latencies. Further, it was predicted that subjects in the speed competition group would work faster and make fewer errors in performance and retention than subjects in the accuracy competition group. This prediction was partially confirmed. The speed competition group performed at a significantly faster rate than the accuracy competition group. However, the speed condition employed in this study did not significantly influence the performance of subjects in either number of errors or in the retention of presented material. Subjects performed faster, but not better. A further hypothesis concerned the relative position of the subjects in relation to their competitor. It had been predicted that subjects in the tied position would make fewer errors than subjects in the win or lose position. While there was some evidence 
that the tied position led to difference in the subjects' use of the "no response" category, there was no support for a difference in the number of errors in performance or retention.

In sum, speed competition was found to enhance efficiency (rate) of performance but was not significantly related to proficiency (errors) in performance.

The present findings are similar to those reported by Clifford, Cleary and Walster (1971). They found no differences among competitive and non-competitive groups either in performance or in retention when the task was a power task. The present study supports that finding. Clifford et al. (1972) hypothesized that there would be a difference in performance if the task were a simple one emphasizing speed. This study found no differences in performance and retention between a power or speed instructional set when the task was of moderate complexity. The only difference was in rate of performance.

A number of explanations may be offered in accounting for the present findings.

one possible explanation is that the instructional set employed was not effective in creating a competitive situation. A major component of competitive performance is motive (Johnson \& Johnson, 1975). Since no measure of competitive motive was employed, the subject's competitiveness within these conditions was not directly assessed but was assumed. It may be questioned whether the subjects viewed 
the treatment conditions as competitive. The nature of the competitive conditions employed was one that involved a "fake" competitor. However, since the treatment conditions were not empirically validated, it may be reasonable to assume that the instructional sets employed were not supported behaviorally. There is some question as to the effectiveness of a remote competitor in affecting a competitive motive among second graders. Social psychological research has suggested that goals which are established by people who are remote from an individual and towards whom they feel no affinity may not be perceived as being relevant to them, and, therefore, not affect their behavior (Cartwright \& Zander, 1953). Research by Clifford (1971) indicates that children do not respond under conditions of superimposed norms.

An alternative to the above explanation was that the treatment was only partially effective in influencing performance and retention. The speed competition instructions did result in significant differences in response latencies. The subjects in the speed competition group did respond significantly faster than subjects in the other two groups. However, this was not accompanied by a reduction in errors. Although this result indicates that the instructional set for speed was effective, it still leaves open the question of whether the competitive set was effective. Whether the initial or alternative explanation of those data is correct appears contingent, as suggested in the preceding discussion, upon the employment of some behavioral measure of competitive motive. 
The present study indicates that an instructional set may be a necessary but not sufficient condition for enhancing performance on a cognitively-related task.

Another possible explanation of the data entails task difficulty. Most studies have employed motor tasks or simple arithmetic problems as competitive tasks (Hurlock, 1927; Maller, 1929). Clifford (1971) employed a digit-letter copying task as her speed task. She speculates that this type of simple task is the only type where competition would be effective. In subsequent research, when a word-building task was employed and competition proved ineffective, she hypothesized that this task was on the high end of the task difficulty continuum and was, in part, the reason competition was ineffective. She suggested that the difficulty factor of the word-building task she employed might have been lowered if definitions of the words employed had been provided. Her explanation of these data, however, is highly speculative since no standard measure of task difficulty has been offered. Since task difficulty appears to be a factor in weighing the effectiveness of competition, more research into task difficulty appears necessary. Whatever the results of such investigations, however, it is apparent that the present task was not a highly difficult one but one of easy-to-moderate complexity. As such, the present results may be viewed as a confirmation of Clifford's findings. In this study the competitive instructional set was effective in increasing the speed at which the task was performed. The performance 
of this task involved a psychomotor component - pushing a button in front of a picture. However, the quality of performance (viz. number of errors) is a cognitively-related function. The competitive set involving speed, therefore, may affect a change in the psychomotor aspect of performance but not in the quality of performance which reflects cognitive processes.

Two other explanations may be considered. Clifford (1972) studied fifth and sixth grade children; this study employed second grade children. It may be suggested that second graders do not possess a sense of competition comparable to that of fifth and sixth graders. This age variable must be viewed both developmentally and educationally. Having had three or four more years to mature and to be exposed to a competitive setting (schools), fifth and sixth graders' performance in a competitive setting may be significantly different than that of second graders. This is supported by the finding of Madsen (1971) and Nelson (1970) who found that American children become more competitive with increasing age and exposure to formal education.

Consideration must also be directed to the possibility that the task itself held the subjects' interest. Clifford, Cleary and Walster (1972) proposed that the effects of competition may be related to a deprivation-satiation factor. "The greater the saturation, the less effective is reinforcement. The more intrinsically competitive the task, the less effective is superimposed competition" (Clifford et al. 
1972). The task employed here had a built-in competitive factor - the subjects received feedback on whether their responses were correct or not. Additional feedback may have been superfluous to the task at hand.

The relative position of the competitor was not a statistically significant factor in this study. This may have been due to the small distance which was established between the competitors. At no point was any subject more or less than four behind or ahead. This may have been too close to establish these positions as separate from the tied condition.

No significant sex differences were found on any of the measures which could be directly analyzed. There were indications, however, that there may be differences between males and females which should be further pursued. Comiskey (1975) found that there was a significant difference between males and females on the strategies employed in a competitive as opposed to non-competitive situation, particularly for females. Females used the "no response" category much more often than did the males in a non-competitive situation. Although this hypothesis could not be analyzed in a direct manner because of the design of the present study, when the male and female experimental groups were compared to their respective non-competitive groups, the female experimental groups showed significant differences in strategy in terms of the use of "no response" as a response choice whereas the male group did not. Both males and females used the "no 
response" category at approximately equal ratios under the competitive conditions. Under the non-competitive condition females used it to a greater extent. This change, then, may be attributed to the difference in the means of the two non-competitive groups. This is further supported by the significant difference in the standard deviation for the experimental female group, especially in the speed tied condition when compared to the females in the non-competitive condition. The standard deviation for the males was not significantly different. These differences may indicate that females employ a different strategy than males in a non-competitive situation but change their strategy when that situation becomes a competitive one. It is of interest to note that there was no concomitant difference in the number of errors made by the male or female groups.

The analysis of these data leads to some suggestions for direction in future research. In dealing with competition, careful note need be given to the effectiveness of the competitive set employed. One way of approaching this criterion would be to employ a performance measure for judging a subject's competitive interest in the task at hand. Mithaug (1973) has suggested that feedback given to the subject be placed behind a screen which the subject would in some way move in order to view his/her relative position. Social game theory employs such a behavioral measure by viewing the person's choice of strategy (McClintock, 1972) or by recording the direction of the subject's string pulling (Madsen, 1971). 
A comparable behavioral measure would provide a means for judging the subject's interest in the comparative aspects of the learning situation.

Supplementing this behavioral measure of competitive motive, McClintock's research on social motive offers additional guidelines for appraising response set. lilclintock has begun to make distinctions between personal motives such as competitive, cooperative, individualistic and altruistic orientations which appear to influence one's response set. It would be of interest to see if subjects who were partialed out as having a particular competitive orientation actually performed better on a competitive learning task than subjects who clearly employed alternative motives.

When using a competitive set involving levels of position in regard to competitor, it is also necessary to partial out the effects of the competitive set from the effects of speed and accuracy instructions. One way to accomplish this goal would be to design research involving another treatment group whose instructions would include speed and accuracy instructions without reference to the relative competitive position of the subjects. This approach would allow a more direct comparison between relative positions and a more equivalent control group. This might also provide a clearer answer to whether the competitive conditions were effective or not.

Additional research is needed in specifying the conditions under which competition is an effective or ineffec- 
tive instructional set. Competition is obviously a complex phenomenon involving difficulty of the task, motive of the subject, identity of the competitor and relative position within competition.

Further exploration must extend to the effects of competition in terms of both internal and external motivation. In addition, it may be asked whether a meaningful laboratory analog to a complex social situation (as school is) can be found. This study has shown that competition may be effective in improving speed of performance without loss of accuracy on a recognition task. This finding does not, however, offer an optimistic view of competition as an effective approach to the solution of complex tasks. Considering the other effects which may be inherent in a competitive set (Johnson \& Johnson, 1976), competition within the school system should be used with caution and care. 
Azrin, N. H., \& Lindsley, D. R. The reinforcement of cooperation between children. Journal of Abnormal Social Psychology, 1956, 52, 100-102.

Blair, G. Ni., Jones, R. S.: sc Simpson, R. H. Educational Psychology (3rd Ed.) New York: Macmillan Company, 1968.

Boneau, C. A. The effects of violations of assumptions underlying the $t$ test. Psychological Bulletin, 1960, 57, 49-64.

Cartwright, D. \& Zander, A. Group Dynamics: Research and Theory, Evanston, Illinois, Row, Peterson \& Company, 1953.

Clifford, M. M. Motivational effects of competition and goal-setting in reward and non-reward conditions. The Journal of Experimental Education, 1971, 22, 11-16.

Clifford, M. M. Effects of competition as a motivational technique in the classroom. American Educational Research Journal, 1972, 2, 123-137.

Clifford, M. M., Cleary, T, A., \& Walster, G. W. Effects of emphasizing competition in classroom-testing procedures. Journal of Educational Research, $1972,65,234-278$.

Comiskey, T. The effects of competitive cues on a learning task. Unpublished manuscript, University of Rhode Island, 1975.

Cottrell, N. B. 1968. Performance in the presence of other human beings: Mere presence, audience, and affiliation effects. In E. C. Simmel, R. A. Hoppe \& G. A. Milton (Eds.) Social Facilitation and Initative Behavior. Boston: A.1lyn \& Bacon, 1968.

Davis, J., Laughlin, P., \& Komorita, S. The social psychology of small groups: Cooperative and mixed motive interaction. In M. Rosenweig \& L. Porter (Eds.) Annual Review of Psychology. Palo Alto, California: Annual Reviews, Inc., 1976.

Deutsch, M. A theory of cooperation and competition. Human Relations, $1949,2,129-152$ (b).

Gallo, P. S., \& McClintock, C. G. Cooperative and competitive behavior in mixed-motive games. Journal of Conflict Resolution, $1965,2,68-78$. 
Greenberg, P. J. Competition in children: An experimental study. American Journal of Psychology, 1932, 44, 221-248.

Hurlock, E. B. Use of group rivalry as an incentive. Journal of Abnormal and Social Psychology, 1927, 22, 278-290.

Johnson, O., \& Johnson, R. Instructional goal structure: Cooperative, competitive or individualistic. Review of Educational Research, 1975, 44, 213-240.

Kagan, S., \& Madsen, M. C. Cooperation and competition of Mexican, Mexican-American, and Anglo-American children of two ages under four instructional sets. Developmental Psychology, 1971, 2, 32-39.

Kelley, H. H., \& Thibaut, J. W. Group problem-solving. In G. Lindzey \& E. Aronson (Eds.) Handbook of Social Psychology (Vol. 4) New York: Addison-Wesley, 1969.

Kelley, H. H., Thibaut, J. W., Radloff, R., \& Mundy, D. The development of cooperation in the "minimal social situation". Psychological Monographs, 1962, 76. (19, Whole No. 538).

Kulberg, J. The effect of social class, age and sex upon the reward value of certain positive reinforcers. Unpublished doctoral dissertation; Peabody College for Teachers, 1967.

Kulberg, J., \& Woulff, N. Sex differences in competitive learning under varying conditions of reinforcement. Unpublished manuscript, 1973. (Available from J. Kulberg, Dept. of Psychology, University of Rhode Island).

Lindsley, 0.R. Experimental analysis of cooperation and competition. In T. Verhave. (Ed.) The Experimental Analysis of Behavior. New York: Appleton-Century-Crofts, 1966.

Lynch, S., \& Rohwer, W. Effects of verbal and pictorial elaborations on associative learning and response learning in a children's P-A task. Journal of Educational Psychology, 1971, 62, 339-344.

McClintock, C. G. Social motivation - A set of propositions. Behavioral Science, 19, 1972, 438-454.

McClintock, C. G., Gallo, P., \& Harrison, A. Some effects of variations in other strategy upon game behavior. Journal of Personality and Social Psychology, 1968, 1, 319-325.

McKee, J., \& Leader, F. The relationship of SES and aggression to the competitive behavior of preschool children. Child Development, 1955, 26, 135-142. 
Madsen, $M$. Cooperative and competitive motivation of children in three Mexican sub-cultures. Psychological Reports, $1967,20,1307-1320$.

Madsen, M. C. Development and cross-cultural differences in the cooperative and competitive behavior of young children. Journal of Cross-Cultural Psychology, 1971, 2, 365-371.

Maller, J. B. Cooperation and competition - An experimental study in motivation. New York: Teachers College, Columbia University, 1929.

Mallory, W. A. Abilities and developmental changes in elaborative strategies in $\mathrm{P}-\mathrm{A}$ learning of young children. Journal of Educational Psychology, 1972, 63, 202-217.

Miller, A. G., \& Thomas, R. Cooperation and competition among Blackfoot Indian and urban Canadian children. Child Development, 1972, 43, 1104-1110.

Mithaug, D. E. The development of procedures for identifying competitive behavior in children. Journal of Experimental Child Psychology, 1973, 16, 76-90.

Nelson, L. I. The development of cooperation and competition in children from ages five to ten years old: Effects of sex, situational determinants, and prior experiences. Doctoral Dissertation, University of Michigan, 1970. University Microfilms No. 71-669.

Nelson, L. I., \& Kagan, S. Competition: The star-spangled scramble. Psychology Today, 1972, 6, 53-56, 90-91.

Norton, D. W. An empirical investigation of some effects of non-normality and deterogeneity of the $F$ distribution. Unpublished doctoral dissertation, State University of Iowa, 1952. Cited by C.F. Iindquist, Design and Analysis of Experiments in Psychology and Education. Boston: Houghton Miffin, 1953.

Palermo, D. S., \& Jenkins, J. J. Word Association Norms: Grade School Through College. Minneapolis: University of Minnesota Press, 1964.

Ryan, T. J., \& Strawbridge, J. E. Effects of observer condition, instructional set, reward schedule, and sex of subject upon performer and observer. Developmental Psychology, $1969,1,474-481$. 
Shapira, A., \& Madsen, M. Cooperative and competitive behavior of Kibbutz and urban children of Israel. Child Development. 1969, 40, 609-615.

Sidowski, J. B. Reward and punishment in a minimum social situation. Journal of Experimental Psychology, 1957, 54, 318-326.

Sidowski, J. B., Wyckoff, L. B., \& Taylor, L, The influence of reinforcement and punishment in a minimal social. situation. Journal of Abnormal and Social Psychology, $1956,52,1 \frac{15-119}{}$

Smith, E. E. Individual versus group goal conflict. Journal of Abnormal and Social Psychology, 1959, 58, $134-137$.

Strong, C. H. Motivation related to performance of physical fitness tests. Research Quarterly, 1963, 34, 497-507.

Weingarten, $D_{1}$, \& Mechner, $F$. The contingency as an independent variable social interaction. In $T$. Verhave (Ed.) The Experimental Analysis of Behavior. New York: AppletonCentury-Crofts, 1966 .

Winer, ${ }_{(2 n d} \cdot \mathrm{J} \cdot$ Statistical Principles $\frac{\text { Sta }}{\text { Experimental }}$ Design

Wrightsman, I. S., O'Connor, J., \& Baker, N. Cooperation and Competition: Readings on Mixed-Motive Games. California: Brooks/Cole, 1972. 
APPENDIX A 
A principle goal of education is to enhance learning in children. In carrying out this objective, educators employ a variety of techniques and approaches. One approach to achieving this goal is to motivate the child to learn through stress on competition. Through spelling bees, gold stars and general excellence medals are common examples of classroom incentives. Further, with greater stress placed on accountability, national norms and standardized achievement tests play a larger role in school systems than ever before. With this stress on competitive performance, it is important to ask what elements are involved in an educationally competitive setting and under what conditions and for which children competition is an effective educational set.

Research directed towards answering these questions must proceed carefully. Competition is a complex and varied phenomena. The number of variables operative within a classroom setting is incalculable. A prudent approach to such an intricate and involved subject would be to view competition and its effects in its simplest form and, from this base, begin to explore the various elements that increase its complexity within a social educational system.

Research literature on competition is marked by diversity in methodology, task design, task difficulty and use of incentives. In addition, competition has been defined in a variety of ways. For example, sutdies of competition have involved a subject working alone, competing with a norms competing with other 
individuals; competing across groups (Clifford, 1971). This diversity in approach has led to a concomitant diversity in results.

\section{Definition}

Competition has generally been defined in contrast to cooperation. This linking of cooperation and competition, common throughout the literature, often places competition in a maladaptive role. The concentration and interest is an elucidating the differences between these approaches rather than exploring and detaching the characteristics each has to offer. The theoretical reasoning for this comes from small group theory which maintains that cooperative behavior helps groups to form and maintain themselves while competition is disruptive to group cohesion (Gallo \& McClintock, 1965, Thibaut \& Kelley, 1959). Research, under this orientation, focuses on the conditions under which people cooperate and explore the factors which interfere with that cooperation.

May and Doobs (1937) defined motivation as being a result of the difference between a person's present position and their drive to achieve greater goals. Cooperation and competition are aimed at the same social end. The difference lies in the group's ability to achieve the goals sought. Thus, it is argued that people will compete when they are striving for the same limited goal and they cannot all share equal amounts. This event occurs only if they have relatively few personal affiliations with their competitors. If the goal can be shared 
and the rules lead to a situation which encourages this sharing, then cooperation is enhanced. Mead (1942) defines competition as the act of striving for what another is simultaneously striving for and cooperation as the act of working together for a common goal.

Deutsch (1949) emphasizes the difference in goal achievement possibilities: A cooperative situation involves "promotivity interdependent goals" where no one in the group can achieve his own goal unless each member of the group can achieve his own. The outcome sought reflects a common good. If a goal situation is defined so that any individual achieving that goal makes it unattainable for the other group members, Deutsch (1949) defines this situation as possessing "contriently interdependent goals" and considers such a situation competitive. In the competitive condition, therefore, when a person strives to increase his chances of attaining a goal, he decreases the chances of another. In analyzing these differences, Deutsch was concerned with group process rather than with effective outcomes and therefore he had little to say in terms of the effect of the competitive situation on the individual.

A useful and prevalent distinction, similar to Deutsch's, has been adapted from mathematical game theory. Referring to goals on rewards attached to the situation, social game theory proposes a distinction between zero sum games and non-zero sum games. Zero sum games are those in which the winnings of one player are evenly balanced by the losses of another (Wrightman, 
1972). Thus, it is an "I win, you lose" situation. This is comparable to many betting situations, sports contests and academic performances. However, in many situations, wins and losses are not equally distributed. The payoffs to both players often add up to more than or less than zero. Furthermore, in non-zero sum games, payoffs generally depend on the choices which both players make. Consequently, their outcomes are interdependent.

Mcclintock (1972) has further refined this latter approach. In focusing on non-zero sum games, he has identified four separate orientations which people can adopt. In situations involving social interdependence, a person's choice can arise from one or a combination of four motives, maximizing one's own gain (individualistic), maximizing another's gain (altruistic); maximizing joint gain (cooperative), and maximizing one's relative gain (competitive). In his competitive approach, therefore, the person is not simply working for as many points as possible (own gain) but is choosing to maximize the difference between his own gain and the other person's gain. Thus, the emphasis is placed on competition with another. In exploring situations which best exemplify this concept, Mcclintock (1972) points to the school system as a prime example of the competitive motive. While Deutsch (1949) and McClintock (1972) have approached competition from a personality orientation, Kelley and Thibaut (1969) view competition/cooperation within a learning theory framework. Competitition is defined in situations in 
which one person is rewarded with the maximum reward while the others receive a minimum reward. A cooperative situation is one in which the rewards that individuals receive depend on performance of the group as a whole. In both contexts, the motivation of individuals is contingent on the system of rewards operating in the situation. Johnson and Johnson (1975) suggest that Kelley and Thibaut's definition is helpful when dealing with extrinsic motivation while Deutsch's definition is more applicable to a situation where the focus is intrinsic motivation.

Within laboratory settings; Weingarten and Meshner (1966) and Lindsley (1966) employed competitive contingencies to identify competitive behavior where one person's reinforcement precludes the reinforcement of another. Mithaug (197.3) also identified competition in terms of the relationship between task performance and competitive contingencies. He further suggests that it be defined in terms of the relationship between one's score and the competitor's score. This provides a link to Mcclintock's (1972) definition of competitive motive.

Competition, as it emerges from this review, can be defined as behavior exhibited in a win-lose situation in which the relative performance of a subject is stressed in relation to the performance of a competitor.

\section{Paradigms for Investigating Competition}

The study of competition has involved three research paradigms, game theory, laboratory settings and academic taskoriented research. 
Game Theory. In game theory, the major emphasis is on social motive. Much of the research concentrates on cooperation and views competition as maladaptive. Results are reported in terms of the proportion of cooperative choices selected (Deutsch, 1958, Wilson \& Bixenstine, 1962, Gallo \& Mcclintock, 1965). The effects of competitive motive are not fully explored and, in fact, are dependent upon the other person's choice.

Perhaps the most frequently used instrument within this approach is the Prisoner Dilemma Game (PDG). Studies involving this instrument emphasize decision-making skills where one person's reward or return is fixed not only by his own choice but by the choice of the other person. The outcome for each is interdependent. A competitive choice would be one in which one player maximized the other persons loss while exploiting their cooperation. There is no clear-cut reward for a competitive approach because there is no clear-cut competitive choice.

McClintock criticizes the PDG paradigm as inadequately delineating the role of motive used in selecting a response strategy. The same motive could lead to either a competitive or cooperative choice. Since motive is the main focus of game behavior, the Maximizing Difference Game (MDG) (McClintock, 1972) and later the Two-Choice Decomposed Game (DG) (Messick \& Mcclintock, 1968) were designed in order to strengthen the competitive choice possibilities and to clarify the motive aspect within the game situation. Four major motives can be ascertaineds maximizing joint gain (cooperation), maximizing other's gain 
(altruism), maximizing one's own gain (individualism), and maximizing relative gain (competition). These instruments (MDG, DG) provide a view of different motives which determine choice in an interdependent social situation. On the Decomposed Game, the interdependence of the players is less obvious because it focuses the player's attention on their own performance. Their outcomes are still interdependent. This approach views competition as it occurs in various social settings but does not encompass the full range of competitive situations. For example, what of the situations in which competition is an established factor and cooperation is not an adaptive response? These instruments reward interdependent performance rather than the single performance of the best competitor. In addition, research involving the Prisoner Dilemma Game, the Maximizing Difference Game, and the Decomposed Game, while helpful in delineating variables that involve choice of competitive motive, are not as informative as to the effects of that choice once it has been made in particular situations.

In a similar theoretical view, Madsen (1967) devised a Cooperation Form Board to study cooperative and competitive motives. The object of this game is to encourage two or more children to cooperate in crossing a marker through circles. Each child has control of a string attached to the marker. He/she must cooperate in order to move it anywhere but toward himself. Competition, within this setting, is again counterproductive and inevitably leads to a decrease in performance. 
"The only rational strategy was a cooperative one" (Madsen, 1967).

Laboratory Settings, Sidowski, Wyckoff and Taborg (1956) studied behavior in a "minimal social situation". Here two people, unknown to each other and isolated from one another, are situated in front of two buttons. They are instructed to press either of these buttons until asked to stop. When the buttons are pushed, they encounter either reward or punishment (shock). Both results are dependent upon the buttons pressed by the other person. This situation is the laboratory parallel of social game situations. Again, the emphasis is on learning to cooperate in a situation in which outcome is dependent upon another person. This paradigm has been employed in studying the development of cooperation in dyads under a variety of conditions (Kelley, Thibaut, Radloff \& Mundy, 1962, Rabinowitz, Kelley \& Rosenblatt, 1966, Sidowsiki, 1957).

Mithaug (1973) suggests a paradigm in which the subjects' competitive behavior is inferred when the person seeks out information concerning their performance in comparison to that of a competitor. In this situation, the subject is rewarded for surpassing a competitor and feedback is provided in terms of the differential score between the two. This can be an extremely useful paradigm for studying the effects of competition within a controlled situation. 
Academic Task-Oriented Research, The aim of academic task-oriented research is to study the effects of competition on various tasks bearing academic application. Most of the early literature focused on a comparison of subject's reactions within competitive situations involving motor tasks (Triplett, 1897, Greenberg, 1932, Chapman \& Feder, 1917). Kagan and Carlson (1975) employed an assertiveness pull scale, Ryan and Strawbridge (1969) a lever pull, Clifford (1971) a digit substitution task. These tasks have their parallel in the Madsen Cooperation Board and Lindsley's stylus and hole task. Clifford (1972) asks, however, whether these results possess real academic analogs. Other approaches have employed tasks which are more open to educational applications. Hurlock (1927) and Maller (1929) focused attention on an addition task as did one of Chapman and Feder's (1917) three tasks. Peplaus' (1973) and House (1974) employed an anagram task while Clifford (1971, 1972) used both a computational task and a word list. Clifford's research is most applicable to educational objectives since it views the effects of competition in a classroom setting, using the classroom as the unit of measure. This provides us with a model for research which can explore the effects of competition within the complex classroom situation. However, it is limited in its ability to isolate and explore the degree to which various factors contribute to enhancing or inhibiting performance under competitive instructions. Since classroom behavior is a function of personal and situational motives, it appears incumbent upon us to demonstrate 
the effects of setting as a singular variable previous to explaining the interrelationship of cojoint operations or motives. Clifford's research provides an approach to classroom-level performance; it ignores the effect of social setting, internal motive and differential individual response to competitive instructions. 
APPENDIX B 
TABLE A

Means and Standard Deviations of Total

Number of Errors Scores for Three Speed Competition Groups,

Three Accuracy Competition Groups,

and a Non-Competitive Group

\begin{tabular}{|c|c|c|c|c|c|c|}
\hline & \multicolumn{2}{|c|}{$\begin{array}{c}1 \\
\text { Win } \\
\end{array}$} & \multicolumn{2}{|c|}{$\begin{array}{c}2 \\
\text { Lose } \\
\end{array}$} & \multicolumn{2}{|c|}{ i ie } \\
\hline & $\bar{x}$ & $\mathrm{~S}$ & $\overline{\mathrm{x}}$ & $S$ & $\bar{x}$ & $S$ \\
\hline Speed & 13.45 & 5.83 & 13.10 & 4.77 & 14.10 & 6.56 \\
\hline Accuracy & 13.25 & 5.22 & 15.2 & 5.38 & 16.1 & 7.37 \\
\hline Non-Comp. & 14.65 & 6.03 & & & & \\
\hline
\end{tabular}

TABLE B

Means and Standard Deviations of "No Response" Measure for Three Speed Competition Groups, Three Accuracy Competition Groups, and a Non-Competitive Group

\begin{tabular}{|c|c|c|c|c|c|c|}
\hline & \multicolumn{6}{|c|}{ Le $v e I s$} \\
\hline & \multicolumn{2}{|c|}{$\begin{array}{c}1 \\
\text { Win } \\
\end{array}$} & \multicolumn{2}{|c|}{$\begin{array}{c}2 \\
\text { Lose } \\
\end{array}$} & \multicolumn{2}{|c|}{$\begin{array}{l}3 \\
\text { Tie }\end{array}$} \\
\hline & $\overline{\mathrm{X}}$ & $S$ & $\overline{\mathrm{X}}$ & $\mathrm{S}$ & $\overline{\mathrm{X}}$ & $\mathrm{S}$ \\
\hline Speed & 1.70 & 2.38 & 1.75 & 2.04 & .50 & 1.14 \\
\hline Accuracy & 1.70 & 2.10 & 2.75 & 2.63 & 1.30 & 1.45 \\
\hline Non-Comp. & 3.80 & 4.86 & & & & \\
\hline
\end{tabular}




\section{TABLE C}

Means and Standard Deviations of Latencies to. Respond for Three Speed Competition Groups,

Three Accuracy Competition Groups, and a Non-Competitive Group

\section{I e v e I s}

\begin{tabular}{|c|c|c|c|c|c|c|}
\hline & \multicolumn{2}{|c|}{$\begin{array}{c}1 \\
\text { Win } \\
\end{array}$} & \multicolumn{2}{|c|}{$\begin{array}{c}2 \\
\text { Lose } \\
\end{array}$} & \multicolumn{2}{|c|}{$\begin{array}{c}3 \\
\text { Tie } \\
\end{array}$} \\
\hline & $\bar{x}$ & $\mathrm{~S}$ & $\overline{\mathrm{X}}$ & $\mathrm{S}$ & $\bar{X}$ & $S$ \\
\hline Speed & 1268.80 & 324.39 & 1268.45 & 209.06 & 1089.95 & 278.60 \\
\hline Accuracy & 1402.55 & 307.58 & 1551.00 & 312.82 & 1459.45 & 376.93 \\
\hline Non-Comp. & 1585.65 & 424.73 & & & & \\
\hline
\end{tabular}

\section{TABLE D}

Means and Standard Deviations of Number

of Errors on Immediate Test for Three Speed Competition Groups, Three Accuracy Competition Groups, and a Non-Competitive Group

\section{I e v e $1 \mathrm{~s}$}

\begin{tabular}{|c|c|c|c|c|c|c|}
\hline & \multicolumn{2}{|c|}{$\begin{array}{c}1 \\
\text { Win } \\
\end{array}$} & \multicolumn{2}{|c|}{$\begin{array}{c}2 \\
\text { Lose } \\
\end{array}$} & \multicolumn{2}{|c|}{ Tie } \\
\hline & $\bar{x}$ & $S$ & $\bar{X}$ & $S$ & $\overline{\mathrm{X}}$ & $S$ \\
\hline Speed & 1.15 & 1.34 & .45 & .82 & .65 & 1.85 \\
\hline Accuracy & .80 & 1.19 & .70 & .92 & 1.10 & 1.51 \\
\hline Non-Comp. & 1.10 & 1.25 & & & & \\
\hline
\end{tabular}


TABLE E

lvieans and Standard Deviations of Number of Errors on Delayed Test for Three Speed Competition Groups, Three Accuracy Competition Groups, and a Non-Competitive Group

\section{$\underline{\mathrm{L} e \mathrm{~V} e \mathrm{l}}$}

\begin{tabular}{|c|c|c|c|c|c|c|}
\hline & \multicolumn{2}{|c|}{$\begin{array}{c}1 \\
\text { Win } \\
\end{array}$} & \multicolumn{2}{|c|}{$\begin{array}{c}2 \\
\text { Lose } \\
\end{array}$} & \multicolumn{2}{|c|}{$\begin{array}{c}3 \\
\text { Tie }\end{array}$} \\
\hline & $\bar{X}$ & $\mathrm{~S}$ & $\bar{X}$ & S & $\bar{X}$ & $S$ \\
\hline Speed & .89 & 1.60 & .69 & 1.43 & 1.06 & 1.98 \\
\hline Accuracy & .98 & 1.71 & 1.11 & 1.59 & .94 & 1.60 \\
\hline Non-Comp. & .84 & 1.33 & & & & \\
\hline
\end{tabular}

TABLE F

Summary Table for $2 \times 3 \times 2$ Factorial Analysis of Total Errors in Performance for Speed Competition and Accuracy Competition Groups

\begin{tabular}{lrcrc}
\hline Source & Sum of Squares & $\begin{array}{c}\text { Degrees of } \\
\text { Freedom }\end{array}$ & $\begin{array}{c}\text { Mean } \\
\text { Square }\end{array}$ & F \\
\hline C & 50.7012 & 1 & 50.7012 & 1.4075 \\
L & 61.4011 & 2 & 30.7006 & 0.8523 \\
S & 28.0344 & 1 & 28.0344 & 0.7783 \\
CL & 33.8010 & 2 & 16.9005 & 0.4692 \\
CS & 48.1345 & 1 & 48.1345 & 1.3363 \\
LS & 8.8677 & 2 & 4.4888 & 0.1231 \\
CIS & 25.8677 & 2 & 12.9338 & 0.3591 \\
K (CLS) & 3890.3711 & 108 & & \\
\hline
\end{tabular}


TABIE G

Summary Table for Dunnett's t Statistic

Comparing the Experimental Conditions to the Non-Competitive Condition

\begin{tabular}{llllllll}
\hline & \multicolumn{3}{c}{ Speed } & & \multicolumn{3}{c}{$\frac{\text { Accuracy }}{3}$} \\
& Win & Lose & Tie & Win & Lose & Tie \\
\hline Non-Competitive & .64 & .82 & .29 & .74 & -.29 & .77 \\
\hline
\end{tabular}

TABIE $\mathrm{H}$

Summary Table for $2 \times 3 \times 2$ Analysis of Variance on Errors on Immediate Test for Speed Competition and Accuracy Competition Groups

\begin{tabular}{lcccc}
\hline Source & Sum of Squares & $\begin{array}{c}\text { Degrees of } \\
\text { Freedom }\end{array}$ & Square & Squar \\
\hline C & 0.4084 & 1 & 0.4084 & 0.2627 \\
L & 3.4667 & 2 & 1.7333 & 1.1150 \\
S & 0.4084 & 1 & 0.4084 & 0.2627 \\
CL & 3.4667 & 2 & 1.7333 & 1.1150 \\
CS & 0.6750 & 1 & 0.6750 & 0.4342 \\
IS & 0.4667 & 2 & 0.2333 & 0.1501 \\
CLS & 1.8000 & 2 & 0.9000 & 0.5789 \\
Full Model & 167.8990 & 108 & 1.5546 & \\
\hline
\end{tabular}


TABLE I

Summary Table for Dunnett's t Statistic Comparing the Experimental Conditions to the Non-Competitive on Errors on Immediate Test of Retention

\begin{tabular}{lccccccc}
\hline & \multicolumn{2}{c}{$\frac{\text { Speed }}{\text { Accuracy }}$} \\
& Win & Lose & Tie & Win & Lose & Tie \\
\hline Non-Competitive & 0 & 1.79 & 1.28 & .89 & 1.15 & .12 \\
\hline
\end{tabular}

TABLE J

Summary Table for $2 \times 3 \times 2$ Analysis of Variance on Errors on the Delayed Test

for Speed Competition and Accuracy Competition Groups

\begin{tabular}{|c|c|c|c|c|}
\hline Source & Sum of Squares & $\begin{array}{c}\text { Degrees of } \\
\text { Freedom }\end{array}$ & $\begin{array}{l}\text { livean } \\
\text { Square }\end{array}$ & $F$ \\
\hline $\begin{array}{l}\text { C } \\
\text { L } \\
\text { S } \\
\text { CL } \\
\text { CS } \\
\text { LS } \\
\text { CLS } \\
\text { Error }\end{array}$ & $\begin{array}{r}0.37119 \\
0.20093 \\
1.72906 \\
1.31726 \\
0.24170 \\
4.98840 \\
2.95683 \\
204.46898\end{array}$ & $\begin{array}{r}1 \\
2 \\
1 \\
2 \\
1 \\
2 \\
2 \\
92\end{array}$ & $\begin{array}{l}0.37119 \\
0.10046 \\
1.72906 \\
0.65863 \\
0.24170 \\
2.49420 \\
1.47842 \\
2.22249\end{array}$ & $\begin{array}{l}0.16701 \\
0.04520 \\
0.77799 \\
0.29635 \\
0.10875 \\
1.12226 \\
0.66521\end{array}$ \\
\hline
\end{tabular}




\section{TABIE $K$}

Summary Table for Dunnett's t Statistic Comparing the Experimental Conditions to the Non-Competitive on Errors on the Delayed Test of Retention

\begin{tabular}{lccccccc}
\hline & \multicolumn{2}{c}{ Speed } & & \multicolumn{3}{c}{ Accuracy } \\
& Win & Lose & Tie & Win & Lose & Tie \\
\hline Non-Competitive & .81 & 1.31 & .55 & .91 & -.86 & -1.26 \\
\hline
\end{tabular}


APPENDIX C 
Raw Data

$\underline{\text { Sex }^{*}}$ Condition ${ }^{*}$ Level ${ }^{*}$ Subject Errors $\underline{N R}$ Latency $I^{*}{ }^{*} T^{*}$

$\begin{array}{lllllllll}1 & 1 & 0 & 01 & 16 & 04 & 1576 & 1 & - \\ 1 & 1 & 0 & 02 & 11 & 00 & 1063 & 2 & 2 \\ 1 & 1 & 0 & 03 & 12 & 07 & 2164 & 0 & \overline{2} \\ 1 & 1 & 0 & 04 & 17 & 00 & 0927 & 2 & 2 \\ 1 & 1 & 0 & 05 & 10 & 06 & 1568 & 0 & -\overline{0} \\ 1 & 1 & 0 & 06 & 10 & 00 & 1494 & 0 & 0 \\ 1 & 1 & 0 & 07 & 09 & 01 & 1406 & 0 & 0 \\ 1 & 1 & 0 & 08 & 28 & 18 & 2346 & 2 & 2 \\ 1 & 1 & 0 & 09 & 14 & 12 & 2008 & 0 & 0 \\ 1 & 1 & 0 & 10 & 15 & 03 & 1773 & 0 & 0\end{array}$

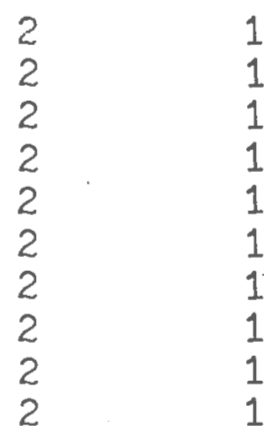

01

02

03

04

05

07

08

09

10

$\begin{array}{lllll}32 & 10 & 2608 & 4 & 2\end{array}$

$\begin{array}{lllll}11 & 00 & 1513 & 0 & 0\end{array}$

$\begin{array}{lllll}17 & 06 & 1403 & 3 & 0\end{array}$

$\begin{array}{lllll}14 & 02 & 1681 & 2 & 0\end{array}$

$\begin{array}{lllll}11 & 00 & 1459 & 0 & 0\end{array}$

$\begin{array}{lllll}16 & 01 & 1329 & 2 & 3\end{array}$

$\begin{array}{lllll}11 & 03 & 1230 & 0 & 0\end{array}$

$\begin{array}{llll}16 & 00 & 1535 & 2\end{array}$

$\begin{array}{llll}16 & 03 & 1542 & 2 \\ 07 & 00 & 1088 & 0\end{array}$

$\begin{array}{ll}1 & 2 \\ 1 & 2 \\ 1 & 2 \\ 1 & 2 \\ 1 & 2 \\ 1 & 2 \\ 1 & 2 \\ 1 & 2 \\ 1 & 2 \\ 1 & 2\end{array}$

101

01

$\begin{array}{lllll}07 & 01 & 1045 & 0 & 0\end{array}$

03

04

05

07

08

09

10

$09 \quad 07 \quad 1443$

$04 \quad 00 \quad 0999$

$03 \quad 00 \quad 1012$

$\begin{array}{lll}17 & 00 & 1508 \\ 17 & 03 & 1204\end{array}$

$\begin{array}{lllll}27 & 02 & 1666 & 4 & 4\end{array}$

1

$1706 \cdot 1759 \quad 0 \quad 0$

1

$17 \quad 00 \quad 0822 \quad 1.0$

$\begin{array}{ll}2 & 2 \\ 2 & 2 \\ 2 & 2 \\ 2 & 2 \\ 2 & 2 \\ 2 & 2 \\ 2 & 2 \\ 2 & 2 \\ 2 & 2 \\ 2 & 2\end{array}$

01

02

03

04

05

08

0900

$\begin{array}{lllll}09 & 00 & 1011 & 0 & 2\end{array}$

$\begin{array}{lllll}0 & 0 & 1010 & 0 & 2\end{array}$

$\begin{array}{lllll}14 & 05 & 1773 & 3 & 0\end{array}$

$\begin{array}{lllll}19 & 00 & 0939 & 0 & 0\end{array}$

$\begin{array}{lllll}18 & 00 & 1119 & 2\end{array}$

$\begin{array}{lllll}12 & 00 & 1264 & 0 & 0\end{array}$

$\begin{array}{lllll}18 & 04 & 1476 & 0 & 0\end{array}$

$\begin{array}{lllll}16 & 05 & 1781 & 2 & 2\end{array}$

08

$\begin{array}{lllll}13 & 01 & 1601 & 3 & 0 \\ 15 & 00 & 1044 & 2 & 0\end{array}$ 
$\underline{\text { Sex }^{*}}$ Condition $^{*}$ Leve $1^{*}$ Subject Errors NR Latency IT DT $^{*}$
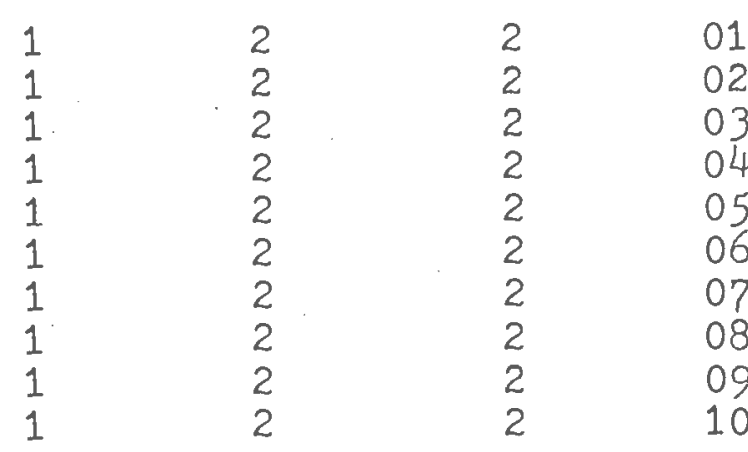

$06 \quad 02$

1111

1108

1439

$\begin{array}{lll}16 & 02 & 1507\end{array}$

$09 \quad 04 \quad 1414$

10

000868

$08 \quad 01 \quad 1005$

$1301 \quad 1393$

$08 \quad 01 \quad 1115$

$22 \quad 01 \quad 1378$

13. $00 \quad 1436$

$0 \quad-$

09

10

$\begin{array}{ll}2 & 01 \\ 2 & 02\end{array}$

03

04

05

06
07

08

09

10

$17 \quad 01 \quad 1320$

20

03

1503

$09 \quad 03 \quad 1258$

18

00

1402

$1900 \quad 1154$

$07 \quad 01 \quad 1095$

$19 \quad 02 \quad 1333$

12000872

$\begin{array}{lll}12 & 05 & 1587 \\ 13 & 00 & 1179\end{array}$

0

0

$0 \cdot 0$

$0 \quad 0$

$0 \quad 0$

10

$0 \quad 0$

20

13

01

02

03

04

05

06

07

08

09

10

$\begin{array}{lllll}10 & 00 & 0651 & 0 & 0\end{array}$

$\begin{array}{lllll}09 & 00 & 0544 & 0 & 0\end{array}$

$\begin{array}{lllll}22 & 00 & 1009 & 3 & 3\end{array}$

$\begin{array}{lllll}13 & 01 & 1283 & 0 & 0\end{array}$

$\begin{array}{lllll}10 & 00 & 0777 & 0 & 0\end{array}$

$\begin{array}{lllll}17 & 00 & 1385 & 2 & 2\end{array}$

$\begin{array}{lllll}17 & 00 & 1214 & 0 & 0\end{array}$

$\begin{array}{lllll}29 & 00 & 0964 & 4 & 5 \\ 06 & 01 & 1007 & 0 & 0\end{array}$

1

3

10

$01 \quad 1465$

0

0

2
2
2
2
2
2
2
2
2
2

2
2
2
2
2
2
2
2
2
2

01

02

03

04

$0900 \quad 1212 \quad 0$

13000798

29

$00 \quad 1394$

$1500 \quad 1179$

19

$00 \quad 088$

13

05
06

07

08

09

17

$\begin{array}{llll}0 & 1411 & 0 & 0\end{array}$

$\begin{array}{lllll}13 & 05 & 1467 & 0 & 0\end{array}$

10

11

$\begin{array}{ll}00 & 0861 \\ 00 & 1029\end{array}$

$\begin{array}{ll}0 & 0 \\ 0 & 2\end{array}$ 
Sex $^{*}$ Condition Level $^{*}$ Subject Errors $\underline{\text { INR Latency }}$ IT LT $^{*}$

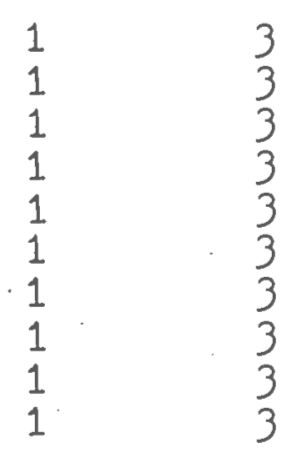

01

02

03

05

05

07

08

09

10

01

02

03

04

05

06

07

08

09

10

01

02

03

04

05

06

07

08

09

10

01

02

03

04

05

06

07

08

09
10 $\begin{array}{ll}15 & 03 \\ 12 & 02\end{array}$

1700

1900

08

12

05

08

19

09

09

08

17

16

18

16

10

24

17

00

00

01

03

10

1718

1445

1176

1494

1350

1983

0997

0990

1721

1190

00

$01 \quad 1403$

$00 \quad 1184$

$04 \quad 1681$

$00 \quad 1277$

$06 \quad 1808$

$02 \quad 1252$

$02 \quad 1670$

$00 \quad 0882$

031684

1400

1301

1707

$09 \quad 00$

1400

1100

$34 \quad 07$

$17 \quad 04$

14

16

06

1355

1501

1950

0987

0993

1246

1948

1639

1671

1793

$\begin{array}{lllll}14 & 01 & 1504 & 0 & 1\end{array}$

$\begin{array}{lllll}09 & 02 & 1508 & 0 & 0\end{array}$

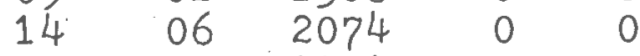

$0900 \quad 1131 \quad 0 \quad 0$

$\begin{array}{lllll}19 & 00 & 1566 & 1 & 0\end{array}$

$\begin{array}{lllll}17 & 05 & 1788 & 1 & 2\end{array}$

$\begin{array}{lllll}15 & 00 & 1232 & 0 & 0\end{array}$

$20 \quad 05 \quad 1740 \quad 1 \quad 4$

$\begin{array}{lllll}13 & 04 & 1634 & 2 & - \\ 15 & 05 & 1760 & 2 & 4\end{array}$ 
Sex $^{*}$ Condition $^{*}$ Leve ${ }^{*}$ Subject Errors $N R$ Latency $I^{*} \underline{D T}^{*}$

$\begin{array}{lllllllll}1 & 3 & 3 & 01 & 12 & 01 & 1394 & 0 & 2 \\ 1 & 3 & 3 & 02 & 26 & 02 & 2303 & 5 & 2 \\ 1 & 3 & 3 & 03 & 22 & 04 & 1960 & 2 & 0 \\ 1 & 3 & 3 & 04 & 13 & 02 & 1878 & 0 & 0 \\ 1 & 3 & 3 & 05 & 17 & 01 & 1840 & 0 & - \\ 1 & 3 & 3 & 06 & 18 & 02 & 1469 & 0 & - \\ 1 & 3 & 3 & 07 & 24 & 04 & 1893 & 2 & 2 \\ 1 & 3 & 3 & 08 & 11 & 00 & 1277 & 0 & 0 \\ 1 & 3 & 3 & 09 & 08 & 00 & 0862 & 0 & 0 \\ 1 & 3 & 3 & 10 & 16 & 00 & 1135 & 0 & 0\end{array}$

$\begin{array}{lllllllll}2 & 3 & 3 & 01 & 07 & 04 & 1123 & 0 & 0 \\ 2 & 3 & 3 & 02 & 12 & 01 & 1434 & 0 & 0 \\ 2 & 3 & 3 & 03 & 13 & 01 & 1184 & 2 & 0 \\ 2 & 3 & 3 & 04 & 32 & 00 & 1700 & 4 & - \\ 2 & 3 & 3 & 05 & 06 & 00 & 1081 & 0 & 0 \\ 2 & 3 & 3 & 06 & 22 & 00 & 1178 & 0 & 4 \\ 2 & 3 & 3 & 07 & 10 & 03 & 1558 & 2 & 0 \\ 2 & 3 & 3 & 08 & 28 & 00 & 1630 & 3 & 3 \\ 2 & 3 & 3 & 09 & 15 & 01 & 1252 & 1 & - \\ 2 & 3 & 3 & 10 & 10 & 00 & 1038 & 1 & 2\end{array}$

\footnotetext{
* sex, $\quad F=1$

condition: Non-competitive $=1$

Speed $=2$

Accuracy $=3$

level: Not Applicable $=0$

Win=1

Lose $=2$

Tie $=3$

NR=No Response

IT=Immediate Test

DT=Delayed Test
} 


\section{Bibliography}

Azrin, N, H, \& Lindsley, D. R. The reinforcement of cooperation between children. Journal of Abnormal Social Psychology. 1956, 52, 100-102.

Berridge, H. An experiment in the psychology of competition. Research Quarterly Supplement, $1935,6.37-42$.

Bixenstine, V. E., Chambers, N., \& Wilson, K. V. Effect of assymmetry in payoff on behavior in a two-person non-zero sum game. Journal of Conflict Resolution, 1964, 8, 151-159.

Blair, G. M., Jones, R. S., \& Simpson, R. H. Educational Psychology (3rd Ed.) New York, The Macmilian Company, 1968.

Boneau, C. A. The effects of violations of assumptions underlying the t test. Psychological Bulletin, 1960, 27, 49-64.

Carment, D. Effects of sex role in a maximizing difference game. Journal of Conflict Resolution, 1974, 18, 461-471.

Cartwright, D., \& Zander, A. Group Dynamics: Research and Theory. Evanston, Illinoiss Row, Peterson \& Company, 1953.

Chapman, J. B., \& Feder, R. B. The effect of external incentives on improvement. Journal of Educational Psychology, $1917,8,469-474$.

Clark, M., Lachowicz, J., \& Wolf, M. A pilot basic education program for school dropouts incorporating a token reinforcement system. Behavior Research and Therapy, $1968,6,183-188$.

Clifford, M. M. Motivational effects of competition and goalsetting in reward and non-reward conditions. The Journal of Experimental Education, 1971, 39.

Clifford, M. M. Effects of competition as a motivational technique in the clasroom. American Educational Research Journal, 1972, 2, 123-137.

Clifford, M. M., Cleary, T. A., \& Walster, G. W. Effects of emphasizing competition in classroom-testing procedures. Journal of Educational Research, 1972, 65, 234-278.

Comiskey, T. The effects of competitive cues on a learning task. Unpublished manuscript, University of Rhode Island, 1975. 
Cottrell, N. B. 1968. Performance in the presence of other human beings. Mere presence, audience, and affiliation effects. In E. C. Simmel, R. A. Hoppe \& G. A. Milton (Eds.) Social Facilitation and Imitative Behavior. Boston: Allyn \& Bacon, 1968.

Cottrell, N, B., Rittle, R. H. , \& Wack, D. I, The presence of an audience and list type as joint determinants of performance in paired-associate learning. Journal of Personality, $1967,35,425-434$.

Cottrell, N. B., Rittle, R. H., \& Wack, D. I. Social facilitation of dominant responses by the presence of an audience and the mere presence of others. Journal of Personality and Social Psychology, 1968, 2, 245-250.

Davis, J., Laughlin, P., \& Komorita, S. The social psychology of small groups: Cooperative and mixed-motive interaction. In M. Rosenweig \& L. Porter (Eds.) Annual Review of Psychology. Palo Alto, California: Annual Reviews, Inc., 1976.

Deutsch, M. An experimental study of the effects of cooperation and competition upon group process. Human Relations, $1949,2,199-231$ (a).

Deutsch, M. A theory of cooperation and competition. Human Relations, $1949, \underline{2}, 129-152$ (b).

Gallo, P, S., \& McClintock, C, G. Cooperative and competitive behavior in mixed-motive games. Journal of Conflict Resolution, $1965,2,68-78$.

Greenberg, P. J. Competition in children: An experimental study. American Journal of Psychology. 1932, 44, 221-248.

Humphrey, J, H. The use of the active game learning medium in the reinforcement of reading skills with fourth grade children. Journal of Special Education, 1967, 1, 369-373.

Hurlock, E. B. Use of group rivalry as an incentive. Journal of Abnormal and Social Psychology, 1927, 22, $278-290$.

Johnson, $0 .$, \& Johnson, $R$. Instructional goal structure: Cooperative, competitive or individualistic. Review of Educational Research, 1975, 44, 213-240.

Kagan, S., \& Carlson, H, Development of adaptive assertiveness in Mexican and United States children. Developmental

Psychology, 1975, 11, 71-78. 
Kagan, S., \& Madsen, M. C. Cooperation and competition of Mexican, Mexican-American, and Anglo-American children of two ages under four instructional sets. Developmental Psychology, 1971, 5, 32-39.

Kagan, S., \& Madsen, M. Experimental analysis of cooperation and competition of Anglo-American and Mexican children. Developmental Psychology, 1972, 1, 49-59.

Kagan, S., \& Madsen, M. C. Rivalry in Anglo-American and Mexican children of two ages. Journal of Personality and Social Psychology, 1972, 24, 214-220.

Kelley, H. H., \& Thibaut, J. W. Group problem-solving. In G. Lindzey and E. Aronson (Eds.) Handbook of Social Psychology (Vol. 4) New York Addison-Wesley, 1969.

Kelley, H. H., Thibaut, J. W., Radloff, R., \& Mundy, D. The development of cooperation in the "minimal social situation". Psychological Monographs, 1962, 76 (19, Whole No. 538).

Komorita, S. S. Cooperative choice in a prisoner's dilemma game Journal of Personality and Social Psychology, 1965, 2, $741-745$.

Kulberg, J. The effect of social class, age and sex upon the reward value of certain positive reinforcers. Unpublished doctoral dissertation, Peabody College for Teachers, 1967.

Kulberg, J., \& Woulff, N. Sex differences in competitive learning under varying conditions of reinforcement. Unpublished manuscript, 1973. (Available from J, Kulberg, Dept. of Psychology, University of Rhode Island).

Lindsley, O, R. Experimental analysis of cooperation and competition. In T. Verhave (Ed.) The Experimental: Analysis of Behavior. New York: Appleton-Century-Crofts, 1966.

Lynch, S., \& Rohwer, W. Effects of verbal and pictorial elaborations on associative learning and response. learning in a children's p-a task. Journal of Educational Psychology, 1971, 62, 339-344.

McClintock, C. G. Game behavior and social motivation in interpersonal settings. In C. NicClintock (Ed.) Experimental Social Psychology, New York: Holt, Rinehart and Winston, $1972(a)$.

McClintock, C. G. Social motivation - A set of propositions. Behavioral Science, 1972, 19, 438-454. 
McClintock, C. G., \& McNeel, S. P. Cross-cultural comparisons of interpersonal motives. Sociometry, 1966, 29, 406-427.

McClintock, C. G., Gallo, P., \& Harrison, A, Some effects of variations in other strategy upon game behavior.

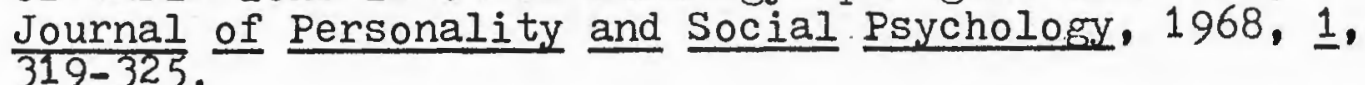

McClintock, C. G., \& Nuttin, J. M., Jr. Development of competitive game behavior in children across two cultures. Journal of Experimental Social Psychology, 1969, 2, 203218.

McNeel, S. P., McClintock, C. G., \& Nuttin, J. M. Effects of sex role in a two-person mixed-motive game. Journal of Personality and Social Psychology, 1972, 24, 372-380.

McKee, J., \& Ieader, F. The relationship of SES and aggression to the competitive behavior of preschool children. Child Development, 1955, 26, 135-142.

Madsen, M. Cooperative and competitive motivation of children in three Mexican sub-cultures. Psychological Reports, $1967,20,1307-1320$.

Madsen, M. C. Development and cross-cultural differences in the cooperative and competitive behavior of young children. Journal of Cross-Cultural Psychology, 1971, 2, 365-371.

Madsen, M. C., \& Shapira, A. Cooperative and competitive behavior of urban Afro-American, Anglo-American, MexicanAmerican, and Mexican village children. Developmental Psychology, 1970, 3.16-20.

Maller, J. B. Cooperation and competition - An experimental study in motivation. New York: Teachers College, Columbia University, 1929.

Mallory, W. A. Abilities and developmental changes in elaborative strategies in p-a learning of young children. Journal of Educational Psychology, 1972, 63, 202-217.

Messick, D. M., \& McClintock, C. G. Motivational bases of choice in experimental games. Journal of Experimental Social Psychology, 1968, 4, 1-25.

Miller, A. G., \& Thomas, R. Cooperation and competition among Blackfoot Indian and urban Canadian children. Child Development, 1972, 43, 1104-1110.

Mithaug, D. E. The development of procedures for identifying competitive behavior in children. Journal of Experimental Child Psychology, 1973, 16, 76-90. 
Mithaug, D, E. The development of cooperation in alternative task situation. Journal of Experimental Child Psychology, $1969,8,143-160$.

Mithaug, D. E., \& Burgess, R. L, Effects of different reinforcement procedures on the establishment of a group response. Journal of Experimental Child Psychology, 1967, 5, 441458.

Mithaug, D. E., \& Burgess, R. L. The effects of different reinforcement contingencies in the development of social cooperation. Journal of Experimental Child Psychology, $1968,6,102-126$.

Nelson, L. I. The development of cooperation and competition in children from ages five to ten years old: Effects of sex, situational determinants, and prior experiences. Doctoral dissertation, University of Michigan, 1970. (University Microfilms No: 71-669).

Nelson, I. I., \& Kagan, S. Competition: The star-spangled scramble. Psychology Today, 1972, 6, 53-56, 90-91.

Nelson, I. I., \& Madsen, H, Cooperation and competition in four year olds as a function of reward contingency and sub-culture. Developmental Psychology, 1969, 1, 340-344.

Norton, D. W. An empirical investigation of some effects of non-normality and deterogeneity of the F distribution. Unpublished doctoral dissertation, State University of Iowa, 1952. Cited by C.F. Lindquist, Design and Analysis of Experiments in Psychology and Education. Boston: Houghton Miffin, 1953.

Palermo, D. S., \& Jenkins, J. J. Word Association Norms: Grade School Through College. Minneapolis; University of Minnesota Press, 1964.

Pepau, A. An experimental study of dating couples, Quoted in Maccoby, E., \& Jacklin, C. The Psychology of Sex Differences. Stanford, California, Stanford University Press, 1974.

Richmond, B., \& Weiner, G. Cooperation and competition among young children as a function of ethnic grouping, grade, sex and reward conditions. Journal of Educational Psychology, 1973, 64, 329-334.

Rosenfeld, G. Some effects of reinforcement on achievement and behavior in a regular classroom. Journal of Educational Psychology, 1972, 63, 183-188. 
Ryan, T. J., \& Strawbridge. J. E. Effects of observer condition, instructio 1 set, reward schedule, and sex of subject upon performer and observer. Developmental. Psychology, 1969, 1, 474-481.

Senior, K., \& Brophy, J. Praise and group competition as motivating incentives for children. Psychological Reports, 1973, 32, 951-958.

Shapira, A., \& Madsen, M. Cooperative and competitive behavior of Kibbutz and urban children of Israel. Child Development, $1969,40,609-615$.

Shapira, A., \& Madsen, M. Between and within group cooperation and competition among Kibbutz and non-Kibbutz children. Developmental Psychology, 1974, 10, 140-145.

Shaw, H. E. Some motivational factors in cooperation and competition. Journal of Personality, 1958, 26, 155-169.

Sidowski, J. B. Reward and punishment in a minimum social situation. Journal of Experimental Psychology, 1957, 24, $318-326$.

Sidowski, J. B., Wyckoff, L, B., \& Taylor, L, The influence of reinforcement and punishment in a minimal social situation. Journal of Abnormal and Social Psychology, 1956, 52, 115-119.

Simon, R. J, et al. Some effects of prearranged performance scores upon levels of aspiration. Journal of Experimental Psychology, 1954, 47, 10-12.

Sims, V. M. The relative influence of two types of motivation on improvement. Journal of Educational Psychology, 1928, 19. $480-484$.

Smith, E. E. Individual versus group goal conflict. Journal of Abnormal and Social Psychology, 1959, 58, $134-137$.

Stone, D. R. Competitive and cooperative set in four verbally-defined social situations. Journal of General Psychology, 1964, 20, 69-73.

Strong, C. F, llotivation related to performance of physical fitness tests. Research Quarterly, 1963, 34, 497-507.

Stephan, $W_{.}$, \& Kennedy, J. An experimental study of interethnic competition in segregated schools. Journal of School Psychology, 1975, 13, 234-235. 
Triplett, N. B. The dynamo nic factors in pacemaking and competition. American zurnal of Psychology, 1897, 2, 507-533.

Weingarten, D., \& Mechner, F. The contingency as an independent variable social interaction. In $T$. Verhave (Ed.) The Experimental Analysis of Behavior. New York: AppletonCentury-Crofts, 1966.

Wheeler, R., \& Ryan, F. Effects of cooperative and competitive classroom environments on the attitudes and achievements of elementary school students engaged in social studies enquiry activities. Journal of Educational Psychology, $1973,65,402-407$.

Whittemore, I. Influence of competition on performance: An experimental study. Journal of Abnormal Social Psychology, $1924,19,236-254$. Winer, B. J. Statistical Frinciples $\frac{\text { in Experimental Design }}{\text { (2nd Ed.) New York: }}$

Wrightsman, I. S., O'Connor, J., \& Baker, N, Cooperation and Competition: Readings on Mixed-liotive Games. California: Brooks/Cole, 1972. 